Article

\title{
Analysis of Transient Interactions between a PWR Nuclear Power Plant and a Faulted Electricity Grid
}

\author{
Vineet Vajpayee *(D), Elif Top and Victor M. Becerra * (D) \\ School of Energy and Electronic Engineering, University of Portsmouth, Portsmouth PO1 3DJ, UK; \\ Elif.Top@myport.ac.uk \\ * Correspondence: vineet.vajpayee@port.ac.uk (V.V.); victor.becerra@port.ac.uk (V.M.B.)
}

Citation: Vajpayee, V.; Top, E.; Becerra, V.M. Analysis of Transient Interactions between a PWR Nuclear Power Plant and a Faulted Electricity Grid. Energies 2021, 14, 1573. https://doi.org/10.3390/en14061573

Academic Editor: Riccardo Amirante

Received: 3 February 2021

Accepted: 9 March 2021

Published: 12 March 2021

Publisher's Note: MDPI stays neutral with regard to jurisdictional claims in published maps and institutional affiliations.

Copyright: (c) 2021 by the authors. Licensee MDPI, Basel, Switzerland. This article is an open access article distributed under the terms and conditions of the Creative Commons Attribution (CC BY) license (https:/ / creativecommons.org/licenses/by/ $4.0 /)$.

\begin{abstract}
This paper presents the transient stability analysis of a pressurised water-type nuclear power plant following faults and disturbances affecting the electricity grid to which it is connected. The modelled nuclear plant consists of various integrated subsystems, such as core neutronics and thermal-hydraulics, piping and plenum, pressuriser, steam generator, turbine, governor, and dynamics shaft, in addition to the turbine-speed controller. The nonlinear nuclear power plant model is linearised at the operating point to acquire a linear model for controller design. The turbine-speed control loop effectively enacts a closed-loop implementation of the nuclear power plant connected to the electric grid. The various transient stability enhancement components such as the power system stabiliser, static var compensator, and static synchronous compensator are employed to test performance during severe contingencies. The interaction between the nuclear power plant, electric grid, and protection system is studied under various scenarios such as single-phase fault, three-phase fault, and permanent load loss. The performance of the nonlinear plant is further observed during load-following operation. The dynamic behaviour of the overall system is analysed using simulations in the MATLAB/Simulink/Simscape environment.
\end{abstract}

Keywords: electric grid; power system; nuclear power plant; pressurised water reactor; transient analysis

\section{Introduction}

Over the last few decades, the dependence on low carbon sources of energy such as nuclear power has grown remarkably. Due to the exigency of carbon-neutral electricity production, it is further expected to grow in the near future. Nuclear power plants are complex systems, generally having large capacities and high safety requirements. The coordination among plants, electric grids, protection systems, and utilities has advanced the operation of nuclear plants in a reserve capacity. The ever-increasing demand and new interconnections make the overall system vulnerable to faults, frequent plant trips, or even blackouts. Uncertainties and disturbances in the electric systems can seriously affect the nuclear power plant, grid, and interconnections. Large disturbances at the grid may cause a wide imbalance between demand and supply and can lead to excursions in the system voltage and frequency. As experienced in the North American blackout on 14 August 2003, such grid disturbances may induce significant transients in nuclear power plants connected to the faulted grid. It resulted, for instance, in large load adjustments, bypass of steam from the turbine generator, the opening of relief valves, and automatic startup of backup generators due to low voltages, all of which led to tripping the affected nuclear power plants [1]. Therefore, to ensure the safety and stability of nuclear plants and associated power systems, it is essential to inspect the effects of grid disturbances on nuclear power plants.

The transient analysis of interactions among different systems has been considered by a few studies in nuclear engineering literature. In the earliest works [2-4], the protection of nuclear power plants has been discussed; however, the mutual influences between the nuclear power plants, grid, and their protection systems have not been sufficiently 
considered. The conventional models of nuclear power plants proposed therein have high computational complexities, which further limited their suitability in large-scale power system dynamic simulations. Linear nuclear power plant models have been employed for short-term stability investigation of the power system for a slow and small range of output variations [5-13]. In these works, the subsystems are given by simplified dynamic equations, which make them preferable in short-term dynamic analysis during small power imbalance conditions. They assume that the excursions in power system frequency and voltage are due to small system disturbances. Thus, the models are not sufficient for longterm dynamics analysis and are inadequate in the case of large disturbances. Moreover, they do not represent the detailed dynamics of a nuclear power plant.

In some recent works [14-17], empirical formulation-based and first principles-based models have been proposed for power system analysis. An optimisation-based method has been put forward by Wang et al. for power systems analysis in advanced pressurised water reactor (PWR) [14]. Wu et al. studied the frequency and voltage excursions and discussed the coordinated control and protection of nuclear power plants and grids [15]. For the over-frequency protection of nuclear power plants, a speed-governing system model was also proposed [16]. Lately, a model for a small modular reactor was suggested to study the power system dynamics [17]. Most of the reported work on nuclear power plant modelling for power system analysis represents only some specific subsystem of the plant. In addition, most of the studies have combined a simplified nuclear plant model with a power system model. A detailed analysis of the integrated nuclear plant model connected with an electric grid is not rigorously carried out using the available power system simulation software packages. The detailed response of plant and network variables have also not been performed in the abovementioned literature as is done in this manuscript. Nonetheless, a complete yet simple integrated nuclear power plant model is required for use in transient analysis, control systems design, and evaluation of the system's response following short-circuits affecting the grid or large and sudden fluctuations in demand.

The interconnection of power systems is beneficial when increasing the reliability of the system and when minimising the operational costs through resource sharing. To improve the overall performance under detrimental situations and to fulfil the comprehensive reliability demands, transient analysis of a detailed nuclear power plant-grid integrated model is required. Based on operational experience, the international atomic energy agency has put forward the characteristics, interactions, and compatibility of nuclear power plants with grids of limited capacity [18]. A reliability study of transmission grids and nuclear power plants during voltage excursions in a transmission system has been studied by Kirby et al. [19]. During electrical disturbances or small interruptions in the power network, the interconnection of nuclear power plants, power systems, and transmission lines makes the overall system susceptible to low-frequency electromechanical oscillations. These oscillations can affect the transient stability of the power system by inducing fluctuations in the line frequency and currents, bus voltages, and generator speeds. The transient stability is further affected by overloading transmission lines due to increased power demands. A power system stabiliser (PSS) is usually employed with the excitation system to maintain synchronism and power flow and to enlarge power transfer limits. The PSS enhances damping during weak transmission situations, accompanying hefty load transfer by modifying the torque angle of the shaft. PSS has been employed to analyse the consequence of a severe power grid fault on the generator of Million Kilowatts nuclear power plant [20]. However, the PSS alone cannot damp oscillations under extreme grid disturbances, and its effectiveness is limited to small excursions around a steady-state point for a nonlinear system [21,22]. Hence, it is essential to advance computationally intelligent controllers for accurate and faster control action.

Flexible alternating current transmission systems (FACTS) are widely employed to stabilise the transmission system. They regulate the network conditions with optimal speed to boost the power transfer capability. FACTS devices increase the controllability and strengthen the steady-state and transient stabilities. During transient oscillations, 
the frequency and voltage control loops regulate the system frequency and voltage to maintain synchronism. Static var compensator (SVC) and static synchronous compensator (STATCOM) are two widely employed shunt-type FACTS devices. The SVC is based on thyristors valves. It regulates the reactive power absorbed from or injected into the power system to control the voltage at its terminals. STATCOM is a voltage-source converterbased device that can act either as a source or as a sink for reactive power to an electricity network. Both power electronics devices work to reduce voltage fluctuations. Moreover, the coordinated action of PSS and SVC, or PSS and STATCOM provides useful means to enhance stability.

The proposed work analyses the transient stability of a PWR-type nuclear power plant connected to an electric grid in the presence of faults and disturbances. The employed model of a PWR-type plant consists of various integrated subsystems, such as core neutronics, thermal hydraulics, piping and plenum, pressuriser, steam generator, turbine, governor, turbine-speed controller, dynamics shaft, actuators, and sensors. This model can be interfaced with a power grid model to enable the study of the dynamic interactions between the grid and the nuclear power plant. To the best of the authors' knowledge, there is no detailed work available in the nuclear energy literature on the systematic incorporation of transient stability enhancement devices in a complete nuclear plant-electric grid model. In this paper, generic PSS and multi-band PSS are connected with SVC and STATCOM to analyse the transient stability of the PWR-type plant connected to the grid in the presence of multiple single-phase faults, multiple three-phase faults, and permanent load loss situations. The dynamic response of the system is discussed using plant and power system variables. The simulations are performed under the MATLAB/Simulink/Simscape environment.

The rest of the paper is organised as follows: Section 2 presents the complete dynamical model of a PWR-type plant. Section 3 presents different transient stability enhancement components. Section 4 discusses the interconnection and coordination of a nuclear power plant with the grid. Section 5 discusses the simulation results. Finally, conclusions are drawn in Section 6.

\section{Mathematical Model of a PWR Nuclear Power Plant}

A simple interconnection of the modelled PWR-type nuclear power plant connected to the electric grid is shown in Figure 1. The various subsystems of the integrated model have been considered in depth in [16,23-25]. The integrated model has been analysed and verified with simulated as well as plant data in [26]. In this work, a dynamic shaft model has been further incorporated in the integrated model [27]. To avoid duplication of published work, the PWR-type nuclear power plant model is presented here in brief. For a detailed description, the readers are advised to refer to $[26,28,29]$. The values of plant parameters, steady-state values, and their detailed definitions are given in $[26,28,29]$.

\subsection{Core Neutronics Model}

\subsubsection{Reactor Point Kinetics}

The reactor point kinetics model consists of power $\left(P_{n}\right)$ and precursor concentration of six groups of delayed neutrons $\left(C_{i n}\right)$. They are normalised by their steady state values and are defined as

$$
\begin{aligned}
\frac{d P_{n}}{d t} & =\frac{\rho_{t}-\sum_{i=1}^{6} \beta_{i}}{\Lambda} P_{n}+\sum_{i=1}^{6} \frac{\beta_{i}}{\Lambda} C_{i n} \\
\frac{d C_{i n}}{d t} & =\lambda_{i} P_{n}-\lambda_{i} C_{i n}, \quad i=1,2, \ldots 6
\end{aligned}
$$

where $\Lambda$ is neutron generation time. $\beta_{i}$ and $\lambda_{i}$ are the fraction of delayed neutrons and decay constant of the $i$ th group, respectively. 


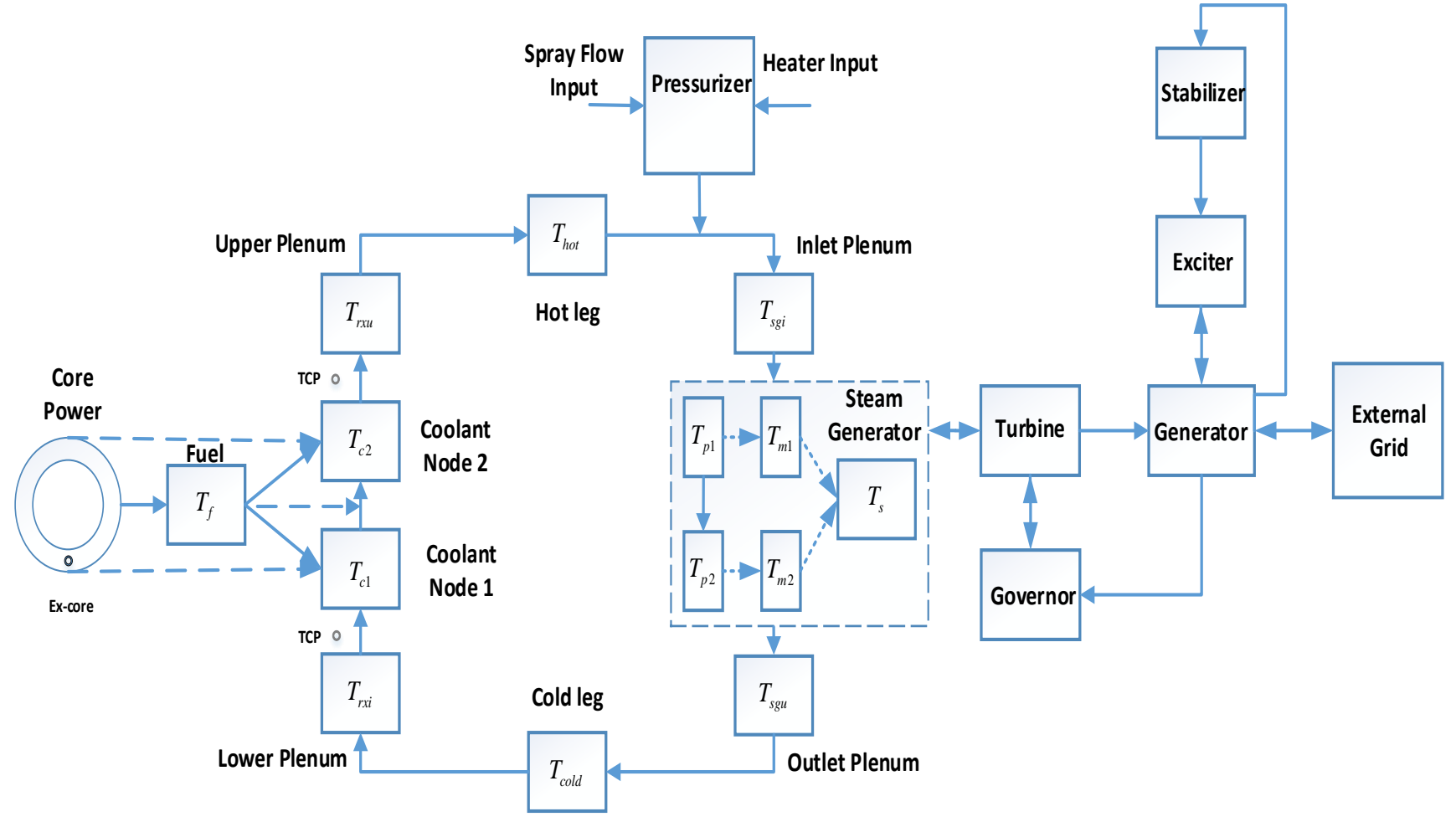

Figure 1. Block diagram representation of a pressurised water reactor (PWR)-type nuclear power plant connected to an electric grid.

\subsubsection{Ex-Core Detectors}

The reactor power can be sensed using ex-core detectors. The ex-core detectors produce an ex-core detector current $\left(i_{l o}\right)$ proportional to the neutronic power, which is amplified by a logarithmic amplifier as follows [30]:

$$
\tau_{1} \tau_{2} \frac{d^{2} i_{l o}}{d t^{2}}+\left(\tau_{1}+\tau_{2}\right) \frac{d i_{l o}}{d t}+i_{l o}=K_{l o} \log _{10}\left(\kappa_{l o} P_{n}\right)
$$

where $\kappa_{l o}$ is a constant. $K_{l o}$ is the logarithmic amplifier gain. $\tau_{1}$ and $\tau_{2}$ are logarithmic amplifier time constants.

\subsubsection{Reactivity Feedback}

The reactivity model incorporates reactivity due to the rod movement and feedback because of the impact of variation in the temperature and pressure of fuel and coolant. The total reactivity $\rho_{t}$ is stated as follows:

$$
\rho_{t}=\rho_{\text {rod }}+\alpha_{f} T_{f}+\alpha_{c} T_{c 1}+\alpha_{c} T_{c 2}+\alpha_{p} p_{p}
$$

where the reactivity due to control the rod $\left(\rho_{\text {rod }}\right)$ is governed by the rod speed $\left(v_{\text {rod }}\right)$ and the rod worth $(G)$ and is given by

$$
\frac{d \rho_{r o d}}{d t}=G v_{r o d}
$$

where $\alpha_{f}, \alpha_{c}$, and $\alpha_{p}$ are reactivity coefficients because of feedback from fuel and coolant temperatures and pressuriser pressure. 


\subsection{Thermal-Hydraulics Model}

\subsubsection{Fuel-Coolant Node}

The core thermal-hydraulics behaviour is determined by Mann's model [23], which correlates the neutronic power to the temperatures of fuel $\left(T_{f}\right)$ to coolant nodes ( $T_{c 1}$ and $T_{c 2}$ ) as follows:

$$
\begin{aligned}
\frac{d T_{f}}{d t} & =H_{f} P_{n}-\frac{1}{\tau_{f}}\left(T_{f}-T_{c 1}\right) \\
\frac{d T_{c 1}}{d t} & =H_{c} P_{n}-\frac{2}{\tau_{r}}\left(T_{c 1}-T_{c i n}\right)+\frac{1}{\tau_{c}}\left(T_{f}-T_{c 1}\right) \\
\frac{d T_{c 2}}{d t} & =H_{c} P_{n}-\frac{2}{\tau_{r}}\left(T_{c 2}-T_{c 1}\right)+\frac{1}{\tau_{c}}\left(T_{f}-T_{c 1}\right)
\end{aligned}
$$

where $\tau_{f}, \tau_{c}$, and $\tau_{r}$ are time constants. $H_{c}$ and $H_{f}$ are the rate of rise of coolant and fuel temperatures, respectively.

\subsubsection{Resistance Temperature Detectors}

Resistance temperature detectors (RTD) are employed to sense the coolant temperature at the inlet $\left(T_{r t d 1}\right)$ and outlet $\left(T_{r t d 2}\right)$ and can be described as follows:

$$
\begin{aligned}
& \frac{d T_{r t d 1}}{d t}=\frac{1}{\tau_{r t d}}\left(-T_{r t d 1}+2 T_{c 1}-T_{r x i}\right) \\
& \frac{d T_{r t d 2}}{d t}=\frac{1}{\tau_{r t d}}\left(-T_{r t d 2}+2 T_{c 2}-T_{r x u}\right)
\end{aligned}
$$

A current signal $\left(i_{r t d}\right)$ can be acquired from the monitored RTD signals as follows: [30]

$$
i_{r t d}=K_{r t d} \frac{\left(\left(\left(T_{r t d 1}+T_{r t d 2}\right) / 2\right)-T_{r x i 0}\right)}{\left(T_{r x u 0}-T_{r x i 0}\right)}+4
$$

where $K_{r t d}$ and $\tau_{r t d}$ are the gain and time constant of RTD, respectively.

\subsection{Piping and Plenum Model}

Hot-leg piping $\left(T_{h o t}\right)$, cold-leg piping $\left(T_{\text {cold }}\right)$, reactor lower-plenum $\left(T_{r x i}\right)$, reactor upper-plenum $\left(T_{r x u}\right)$, steam generator inlet-plenum $\left(T_{s g i}\right)$, and steam generator outletplenum $\left(T_{\text {sgu }}\right)$ can be represented as follows [23]:

$$
\begin{aligned}
\frac{d T_{r x u}}{d t} & =\frac{1}{\tau_{r x u}}\left(T_{c 2}-T_{r x u}\right) \\
\frac{d T_{\text {hot }}}{d t} & =\frac{1}{\tau_{\text {hot }}}\left(T_{r x u}-T_{\text {hot }}\right) \\
\frac{d T_{\text {sgi }}}{d t} & =\frac{1}{\tau_{\text {sgi }}}\left(T_{\text {hot }}-T_{\text {sgi }}\right) \\
\frac{d T_{\text {sgu }}}{d t} & =\frac{1}{\tau_{\text {sgu }}}\left(T_{p 2}-T_{\text {sgu }}\right) \\
\frac{d T_{\text {cold }}}{d t} & =\frac{1}{\tau_{\text {cold }}}\left(T_{\text {sgu }}-T_{\text {cold }}\right) \\
\frac{d T_{r x i}}{d t} & =\frac{1}{\tau_{r x i}}\left(T_{\text {cold }}-T_{r x i}\right)
\end{aligned}
$$

where $\tau_{r x u}, \tau_{r x i}, \tau_{\text {hot }}, \tau_{\text {cold }}, \tau_{\text {sgu }}$, and $\tau_{\text {sgi }}$ denote time constants. 


\subsection{Steam Generator Model}

A five-node model can suitably describe the steam-generator (SG), in which the primary coolant node (PCL) $\left(T_{p 1}\right.$ and $\left.T_{p 2}\right)$ and metal tube node (MTL) $\left(T_{m 1}\right.$ and $T_{m 2}$ ) are given by two nodes each and the secondary coolant node (SCL) is given by one node [24]. It is given as follows:

$$
\begin{aligned}
\frac{d T_{p 1}}{d t} & =\frac{1}{\tau_{p 1}}\left(T_{s g i}-T_{p 1}\right)-\frac{1}{\tau_{p m 1}}\left(T_{p 1}-T_{m 1}\right) \\
\frac{d T_{p 2}}{d t} & =\frac{1}{\tau_{p 2}}\left(T_{p 1}-T_{p 2}\right)-\frac{1}{\tau_{p m 2}}\left(T_{p 2}-T_{m 2}\right) \\
\frac{d T_{m 1}}{d t} & =\frac{1}{\tau_{m p 1}}\left(T_{p 1}-T_{m 1}\right)-\frac{1}{\tau_{m s 1}}\left(T_{m 1}-T_{s}\right) \\
\frac{d T_{m 2}}{d t} & =\frac{1}{\tau_{m p 2}}\left(T_{p 2}-T_{m 2}\right)-\frac{1}{\tau_{m s 2}}\left(T_{m 2}-T_{s}\right)
\end{aligned}
$$

where $\tau_{p 1}, \tau_{p 2}, \tau_{p m 1}, \tau_{p m 2}, \tau_{m p 1}, \tau_{m p 2}, \tau_{m s 1}$, and $\tau_{m s 2}$ denote the time constants. SCL represents the steam pressure $\left(p_{s}\right)$ as follows:

$$
\frac{d p_{s}}{d t}=\frac{1}{K_{s}}\left[U_{m s 1} S_{m s 1}\left(T_{m 1}-T_{s}\right)+U_{m s 2} S_{m s 2}\left(T_{m 2}-T_{s}\right)-\left(\dot{m}_{s o} h_{s s}-\dot{m}_{f w} c_{p f w} T_{f w}\right)\right]
$$

where $S_{m s 1}$ and $U_{m s 1}$ are the effective heat transfer area and the heat transfer coefficient from MTL 1 to SCL, respectively. Similar definitions are valid for $S_{m s 2}$ and $U_{m s 2}$. $c_{p f w}$ is the specific heat of feed water. $T_{f w}$ is the temperature of feed water. $\dot{m}_{f w}$ and $\dot{m}_{s o}$ denote the mass flow rate of feed water and steam, respectively. The constant $K_{s}$ is defined as follows:

$$
K_{s}=m_{w s} \frac{\partial h_{w s}}{\partial p_{s}}+m_{s s} \frac{\partial h_{s s}}{\partial p_{s}}-m_{w s}\left(\frac{h_{w s}-h_{s s}}{v_{w s}-v_{s s}}\right) \frac{\partial v_{s s}}{\partial p_{s}}
$$

where $m_{w s}, h_{w s}$, and $v_{w s}$ denote the mass, enthalpy, and specific volume of water in the secondary lump, respectively. Similarly, $m_{s s}, h_{s s}$ and $v_{s s}$ are the parameters for steam in the SCL.

\subsection{Pressuriser Model}

The pressuriser pressure $\left(p_{p}\right)$ is given by balancing the volume and energy of water and steam mixture besides steam compressibility as follows [25]:

$$
\frac{d p_{p}}{d t}=\frac{Q_{h e a t}+\dot{m}_{s u r}\left(\frac{p_{p} v_{s}}{J_{p} C_{1 p}}+\frac{h_{\bar{w}}}{C_{1 p}}\right)+\dot{m}_{s p r}\left(h_{s p r}-h_{w}+\frac{h_{\bar{w}}}{C_{1 p}}+\frac{p_{p} v_{w}}{J_{p} C_{1 p}}\right)}{m_{w}\left(K_{3 p}+\frac{K_{4 p} p_{p}}{J_{p}}\right)+\frac{m_{s} K_{4 p} p_{p}}{J_{p}}-\frac{V_{w w}}{J_{p}}+\frac{C_{2 p}}{C_{1 p}}\left(h_{\bar{w}}+\frac{p_{p} v_{s}}{J_{p}}\right)}
$$

where $Q_{\text {heat }}$ is rate of heat addition by heater, $\dot{m}_{s p r}$ is mass spray flow rate, and $\dot{m}_{s u r}$ is mass surge flow rate. $m_{w}, d_{w}, h_{w}$, and $v_{w}$ are mass, density, enthalpy, and specific volume of water. Similarly, $m_{s}, d_{s}$, and $v_{s}$ denote the parameters for steam. $h_{\bar{w}}$ and $h_{s p r}$ are the latent heat of vaporisation and enthalpy of spray, respectively. $J_{p}$ is the conversion factor, and $V_{w}$ is water volume. The mass surge flow rate is given by the coolant temperatures at different nodes as follows:

$$
\dot{m}_{\text {sur }}=\sum_{j=1}^{N} V_{j} \vartheta_{j} \frac{d T_{j}}{d t}
$$

where $V_{j}$ is volume and $\vartheta_{j}$ is the slope of coolant density versus temperature curve for the $j$ th node. 
The equation of water level $\left(l_{w}\right)$ in the pressuriser is derived by balancing the mass equations on water and steam phase as follows:

$$
\frac{d l_{w}}{d t}=\frac{1}{d_{s} A_{p}}\left(\left(A_{p}\left(l-l_{w}\right) K_{2 p}-\frac{C_{2 p}}{C_{1 p}}\right) \frac{d p_{p}}{d t}+\frac{1}{C_{1 p}^{2}}\left(C_{2 p} \frac{d p_{p}}{d t}-\dot{m}_{s u r}-\dot{m}_{s p r}\right)+\frac{\dot{m}_{s u r}}{C_{1 p}}\right)
$$

where $A_{p}$ is the cross-sectional area and $l$ is the length of the pressuriser. The other variables are defined as follows:

$$
\begin{aligned}
& C_{1 p}=\frac{d_{w}}{d_{s}}-1 ; \\
& C_{2 p}=A_{p}\left(l-l_{w}\right) \frac{d_{w}}{d_{s}} K_{2 p}+A_{p} l_{w} K_{1 p} ; \\
& K_{1 p}=\frac{\partial d_{w}}{\partial p_{p}} ; K_{2 p}=\frac{\partial d_{s}}{\partial p_{p}} ; K_{3 p}=\frac{\partial h_{w}}{\partial p_{p}} ; K_{4 p}=\frac{\partial v_{s}}{\partial p_{p}} .
\end{aligned}
$$

\subsection{Turbine-Governor Model}

\subsubsection{Turbine}

The turbine model is comprised of the high-pressure, intermediate-pressure, and low-pressure turbines. These are given by the following [16]:

$$
\begin{aligned}
& \frac{d^{2} P_{h p}}{d t}+\left(\frac{O_{r v}+\tau_{i p}}{\tau_{h p} \tau_{i p}}\right) \frac{d P_{h p}}{d t}+\frac{O_{r v} P_{h p}}{\tau_{h p} \tau_{i p}}=\frac{O_{r v} F_{h p} \overline{\dot{m}}_{s o}}{\tau_{h p} \tau_{i p}}+\left(\frac{\left(1+\kappa_{h p}\right) F_{h p}}{\tau_{h p}}\right) \frac{d \bar{w}_{s o}}{d t} \\
& \frac{d^{2} P_{i p}}{d t}+\left(\frac{O_{r v} \tau_{h p}+\tau_{i p}}{\tau_{h p} \tau_{i p}}\right) \frac{d P_{i p}}{d t}+\frac{O_{r v} P_{i p}}{\tau_{h p} \tau_{i p}}=\frac{O_{r v} F_{i p} \overline{\tilde{m}}_{s o}}{\tau_{h p} \tau_{i p}} \\
& \frac{d^{3} P_{l p}}{d t}+\left(\frac{O_{r v} \tau_{h p}+\tau_{i p}}{\tau_{h p} \tau_{i p}}+\frac{1}{\tau_{l p}}\right) \frac{d^{2} P_{l p}}{d t}+\left(\frac{O_{r v}\left(\tau_{l p}+\tau_{h p}\right)+\tau_{i p}}{\tau_{h p} \tau_{i p} \tau_{l p}}\right) \frac{d P_{l p}}{d t}+\frac{O_{r v} P_{l p}}{\tau_{h p} \tau_{i p} \tau_{l p}}=O_{r v} F_{l p} \overline{\dot{m}}_{s o}
\end{aligned}
$$

where $O_{r v}$ is the valve opening degree. $\kappa_{h p}$ is high-pressure natural power overshooting coefficient. $\tau_{h p}, F_{h p}$, and $P_{h p}$ denote the volume time constant, fraction of steady-state power output, and mechanical power output of a high-pressure turbine, respectively. Similar definitions are valid for $\tau_{i p}, F_{i p}$, and $P_{i p}$ for the intermediate-pressure turbine and $\tau_{l p}, F_{l p}$, and $P_{l p}$ for the low-pressure turbine. The total mechanical output of turbine $\left(P_{t u r}\right)$ is computed as follows:

$$
P_{t u r}=P_{h p}+P_{i p}+P_{l p}
$$

\subsubsection{Turbine-Governor Valve}

The steam flow rate is related to the turbine-governor control valve coefficient $\left(C_{t g}\right)$ as follows:

$$
\dot{m}_{s o}=C_{t g} p_{s}
$$

where the steam flow is $\overline{\dot{m}}_{s o}=\frac{\dot{m}_{s o}}{\dot{m}_{s o r}}$. The $\dot{m}_{s o r}$ denotes the rated steam mass flow rate. The valve coefficient can be adjusted using the input signal $\left(u_{t g}\right)$ as follows:

$$
\frac{d^{2} C_{t g}}{d t^{2}}+2 \zeta_{t g} \omega_{t g} \frac{d C_{t g}}{d t}+\omega_{t g}^{2} C_{t g}=\omega_{t g}^{2} K_{t g} u_{t g}
$$

where $\zeta_{t g}$ is the damping ratio, $\omega_{t g}$ is the natural frequency of oscillation, $K_{t g}$ is the gain in the turbine-governor valve.

\subsection{Dynamic Shaft Model}

The dynamic shaft model of a synchronous machine can be described by a dynamic mass-spring mode [27]. It contains low-, intermediate-, and high-pressure turbine masses; 
exciter mass; and machine rotor. The high-pressure turbine mass-spring model is given by the following:

$$
\begin{gathered}
\dot{\delta}_{h p}=\Omega_{b}\left(\omega_{h p}-\omega_{s}\right) \\
\dot{\omega}_{h p}=\frac{q_{t u r}-D_{h p}\left(\omega_{h p}-\omega_{s}\right)-D_{h i}\left(\omega_{h p}-\omega_{i p}\right)+K_{h p}\left(\delta_{i p}-\delta_{h p}\right)}{2 H_{h p}}
\end{gathered}
$$

where $\Omega_{b}$ is base synchronous frequency, $\omega_{s}$ is reference frequency, $q_{t u r}$ is turbine torque related with turbine power as $P_{t u r}=q_{t u r} \omega_{t u r}$, and $q_{e}$ is electric torque. $\delta_{h p}$ is rotor angle, $\omega_{h p}$ is frequency, $D$ is the turbine damping coefficient, $K_{h p}$ is the angle coefficient, and $H_{h p}$ is the inertia constant for a high-pressure turbine. Similar definitions hold for an intermediate-pressure turbine, a low-pressure turbine, the machine rotor, and the exciter denoted by subscripts $i p, l p, m r$, and $e x$, respectively. The turbine dampings for highintermediate, intermediate-low, low-rotor, and rotor-exciter are denoted as $D_{h i}, D_{i l}, D_{l r}$, and $D_{r e}$, respectively.

The intermediate-pressure turbine mass-spring model is given by the following:

$$
\begin{gathered}
\dot{\delta}_{i p}=\Omega_{b}\left(\omega_{i p}-\omega_{s}\right) \\
\dot{\omega}_{i p}=\frac{-D_{i p}\left(\omega_{i p}-\omega_{s}\right)-D_{h i}\left(\omega_{i p}-\omega_{h p}\right)-D_{i l}\left(\omega_{i p}-\omega_{l p}\right)+K_{h p}\left(\delta_{h p}-\delta_{i p}\right)+K_{i p}\left(\delta_{l p}-\delta_{i p}\right)}{2 H_{i p}}
\end{gathered}
$$

The low-pressure turbine mass-spring model is given by the following:

$$
\begin{gathered}
\dot{\delta}_{l p}=\Omega_{b}\left(\omega_{l p}-\omega_{s}\right) \\
\dot{\omega}_{l p}=\frac{-D_{l p}\left(\omega_{l p}-\omega_{s}\right)-D_{i l}\left(\omega_{l p}-\omega_{i p}\right)-D_{l r}\left(\omega_{l p}-\omega_{m r}\right)+K_{i p}\left(\delta_{i p}-\delta_{l p}\right)+K_{l p}\left(\delta_{m r}-\delta_{l p}\right)}{2 H_{l p}}
\end{gathered}
$$

The machine rotor mass-spring model is given by the following:

$$
\dot{\delta}_{m r}=\Omega_{b}\left(\omega_{m r}-1\right)
$$

$\dot{\omega}_{m r}=\frac{-q_{e}-D_{m r}\left(\omega_{m r}-\omega_{s}\right)-D_{l r}\left(\omega_{m r}-\omega_{l p}\right)-D_{r e}\left(\omega_{m r}-\omega_{e x}\right)+K_{l p}\left(\delta_{l p}-\delta_{m r}\right)+K_{e x}\left(\delta_{e x}-\delta_{m r}\right)}{2 H}$

The exciter mass-spring model is given by the following:

$$
\begin{gathered}
\dot{\delta}_{e x}=\Omega_{b}\left(\omega_{e x}-\omega_{s}\right) \\
\dot{\omega}_{e x}=\frac{-D_{e x}\left(\omega_{e x}-\omega_{s}\right)-D_{r e}\left(\omega_{e x}-\omega\right)+K_{e x}\left(\delta-\delta_{e x}\right)}{2 H_{e x}}
\end{gathered}
$$

\subsection{Turbine-Speed Control Loop}

The control loop structure of the turbine-speed system is depicted in Figure 2, in which the speed can be controlled using a turbine-governor valve. The valve regulates the steam flow to modify the speed $[25,26]$. The PI controller output of the configuration can be stated as follows:

$$
u_{t g}=\left(K_{P, t g}+\frac{K_{I, t g}}{s}\right)\left(\omega_{r e f}-\omega_{m r}\right)
$$

where $K_{P, t g}$ and $K_{I, t g}$ are the proportional and integral gain, respectively. 


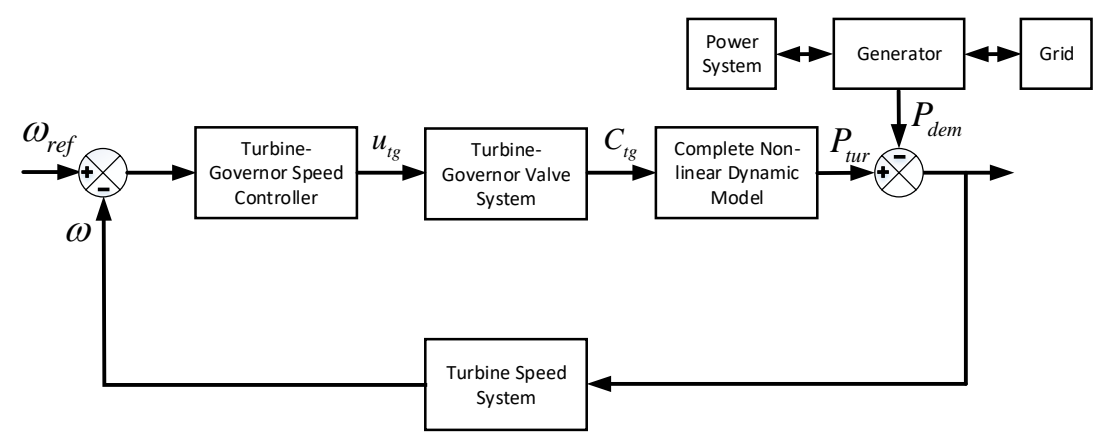

Figure 2. Block diagram of turbine-speed control loop.

\section{Transient Stability Enhancement Components}

The transient stability of a system is given as its capability to maintain a stable condition after large disturbances [31]. Various methods are available to improve the transient stability of power systems, such as fast-acting exciters, power system stabilisers, and FACTS devices.

\subsection{Automatic Voltage Regulator}

The automatic voltage regulator (AVR) is a power system controller that is a part of the excitation system of the generator. It regulates the terminal voltage by modifying the exciter voltage, which in turn regulates the power factor of the machine as well as reactive power generation. The AVR tries to maintain the system voltage within the desired output in steady-state as well as in transient situation to make certain that the generator remains synchronised to the grid system after grid faults. It provides the lag sensitivity to vary the field voltage of the generator rapidly. Nevertheless, the usage of an AVR can prompt the retention of long-term low-frequency oscillation, and thus, this may affect power system equipment and it may reduce the system performance.

\subsection{Power System Stabiliser}

The power system stabiliser (PSS) is a vital tool to enhance overall system stability [32]. Its wide usage is due to its low cost and good performance over a broad span of operating conditions. The central purpose of a PSS is to alleviate any undamped power oscillations restricting the steady-state transfer capability. The working principle of a PSS is to generate an electrical torque in phase with the rotor speed deviations and to include damping to the generator rotor oscillations by regulating its excitation using stabilising signals. Here, two of the known variants (generic PSS and multiband PSS) are considered in the study.

\subsubsection{Generic Power System Stabiliser}

The generic PSS (GPSS) is comprised of a gain block, low-pass and high-pass filters, an output limiter, and a phase-compensation system [32]. The block diagram of a GPSS is depicted in Figure 3. The input to the GPSS is the speed deviation signal coming from the synchronous machine, which in turn is derived using the difference between the output of mechanical power and electrical power. The overall gain determines the damping torque by a GPSS. The low frequencies are eliminated using a wash-out high-pass filter for which the time constant should permit frequency shaping of the input. Generally, an inherent lag occurs between the field excitation voltage and the torque of the machine due to the introduction of a PSS. To compensate for this phase lag, a phase-compensation system consisting of a cascade of two first-order lead-lag transfer functions is employed. However, if disturbance is extreme, then the lead-lag function reduces the over-response of the damping signal of the PSS. The output signal of a GPSS is an output-limited stabilisation voltage signal that is fed to the excitation system to modulate the generator field voltage. 


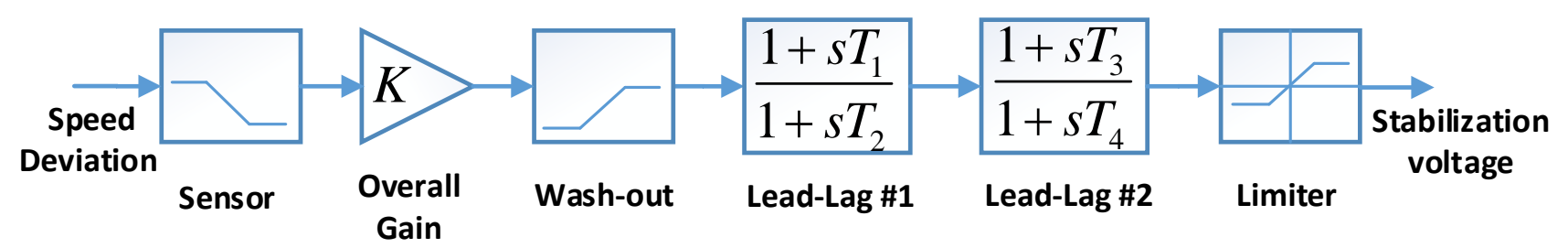

Figure 3. Block diagram representation of the generic power system stabiliser (PSS).

\subsubsection{Multi-Band Power System Stabiliser}

Multiband PSS (MBPSS) adjusts the working band to control different modes of oscillations. It separates the incoming speed deviation signal of the synchronous machine using three separate filters, high-pass, intermediate-pass, and low-pass filters, into high, intermediate, and low-frequency modes of oscillations, respectively [33]. The block diagram of MBPSS is shown in Figure 4. The MBPSS examines the stability in local-mode, inter-areamode, and global-mode of oscillation. In the local-mode, the oscillations occur between a unit and the rest of the generating station, and it is dealt with using the high-pass filter. The inter-area-mode oscillations occur between two groups of generation plants, and they are dealt with using the intermediate-pass filter. The global-mode oscillations take place in all the generators in the isolated power system, and they are dealt with using the low-pass filter. This is in direct contrast to the GPSS, which focuses only on the local-mode instability of the system. Finally, the outputs of all three bands are summed and passed through an output limiter to produce the MBPSS output signal.

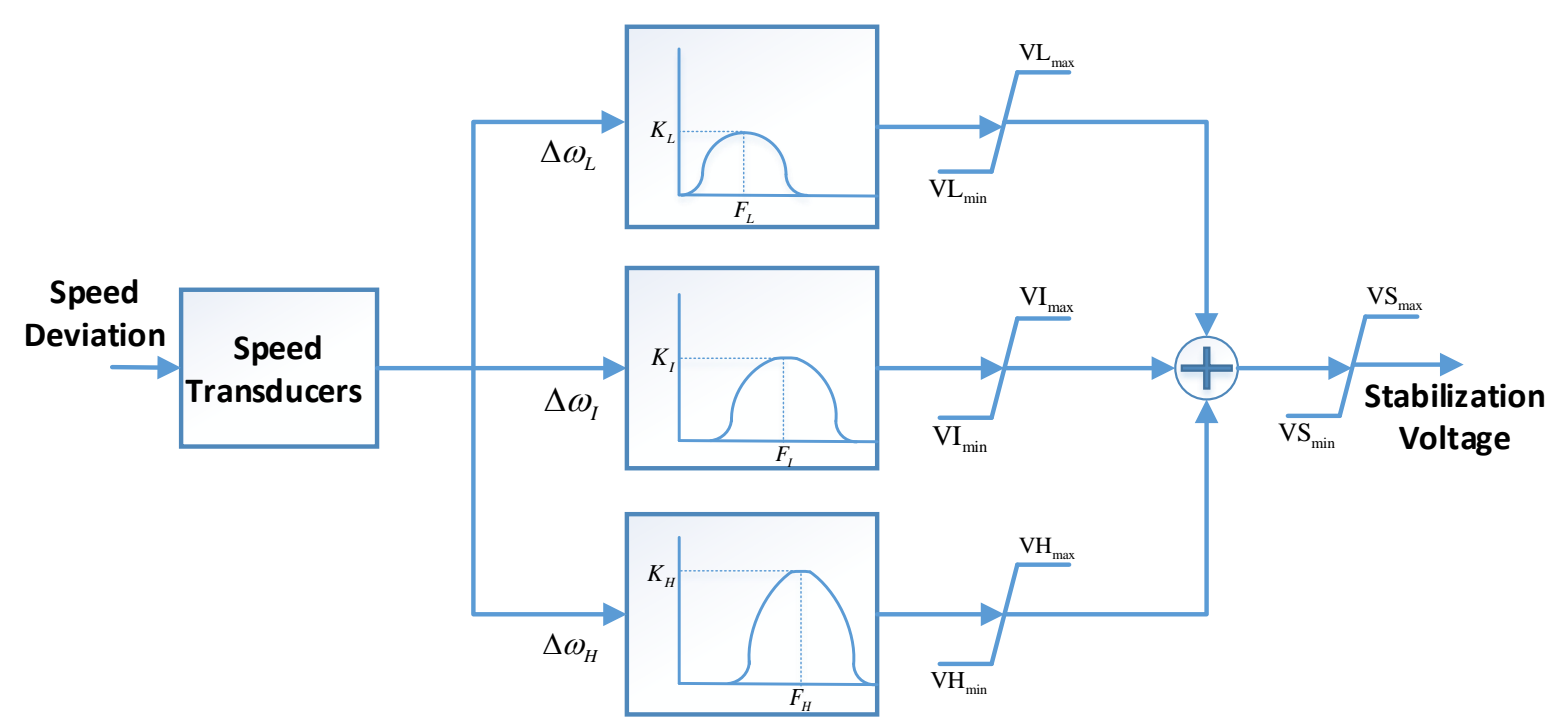

Figure 4. Block diagram representation of the multi-band PSS.

\subsection{Flexible AC Transmission System}

Flexible AC transmission system (FACTS) devices can furnish series or shunt compensation to the reactance of the lines to which they are connected. These devices also provide damping of oscillations in the power grid [34]. Thus, they can reduce the power delivery costs, improve grid stability, and enhance the controllability of the networks. In this work, the shunt compensation is studied through static var compensator and static synchronous compensator. 


\subsubsection{Static Var Compensator}

The static var compensator (SVC) is a shunt-type device regulating the voltage and power flow and can enhance the transient stability on power grids. According to the system reference voltage, the SVC either injects or absorbs reactive power to regulate the voltage on the network. The SVC provides reactive power to the system and acts capacitive if the system voltage is lower than the reference voltage. On the contrary, the SVC absorbs reactive power from the system and acts inductive if the system voltage is higher than the reference voltage [35]. A simplified single-wire circuit diagram of an SVC using the thyristor controlled reactor and thyristor switched capacitor is illustrated in Figure 5. The SVC system comprises banks of three-phase capacitors and inductors that are linked to the secondary side of a coupling transformer. The regulating system of the SVC comprises a pulse generator, a synchronising unit, a voltage measurement unit, a voltage regulator, and a distribution unit.

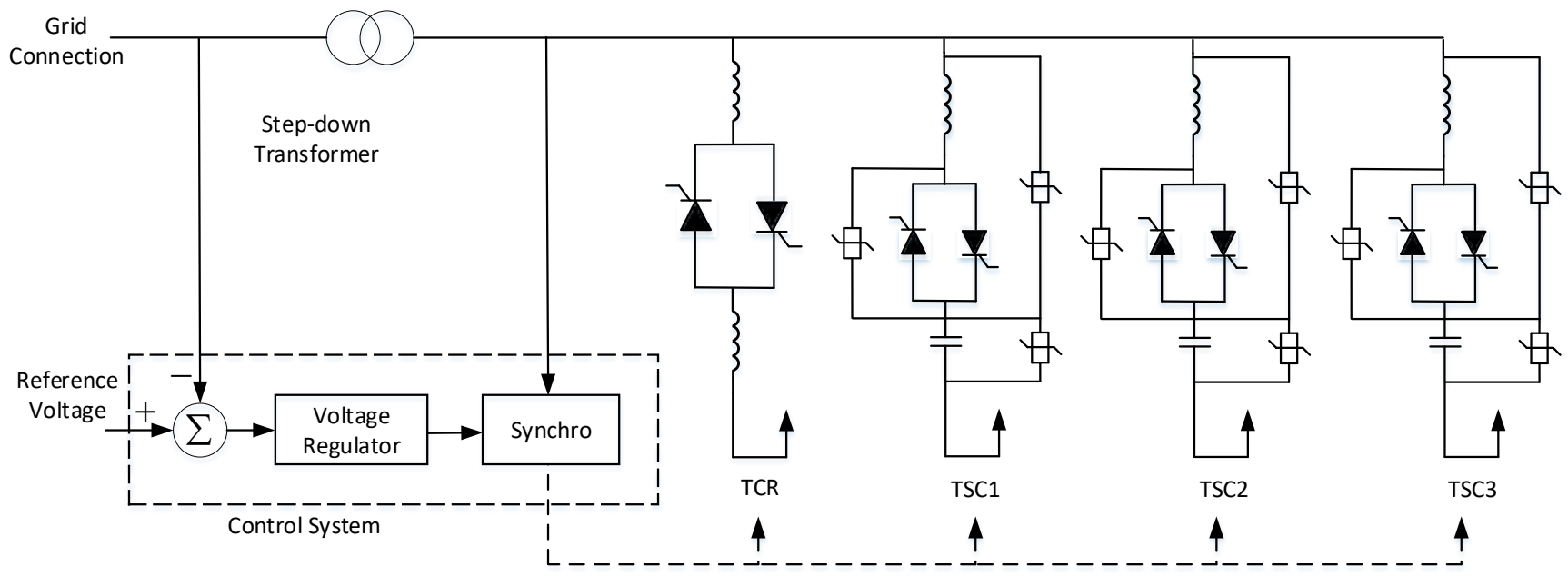

Figure 5. Block diagram representation of the static var compensator.

\subsubsection{Static Synchronous Compensator}

The static synchronous compensator (STATCOM) is a voltage source converter (VSC)based FACTS device. In addition to a VSC, it consists of a coupling transformer and a controller [35]. A simplified single-line diagram of a STATCOM is illustrated in Figure 6. The STATCOM autonomously regulates system voltage by either absorbing or generating reactive power. Opposite to the SVC, the STATCOM output current can be regulated independently from the AC system voltage. STATCOM has a dynamic response time of less than $10 \mathrm{~ms}$ compared to the SVC, which has a response of around 20 to $30 \mathrm{~ms}$. Over other shunt-type compensators, the STATCOM has a possible active harmonic filter capability and offers equal lag and lead output. It also provides fast response and continuous reactive power control. 


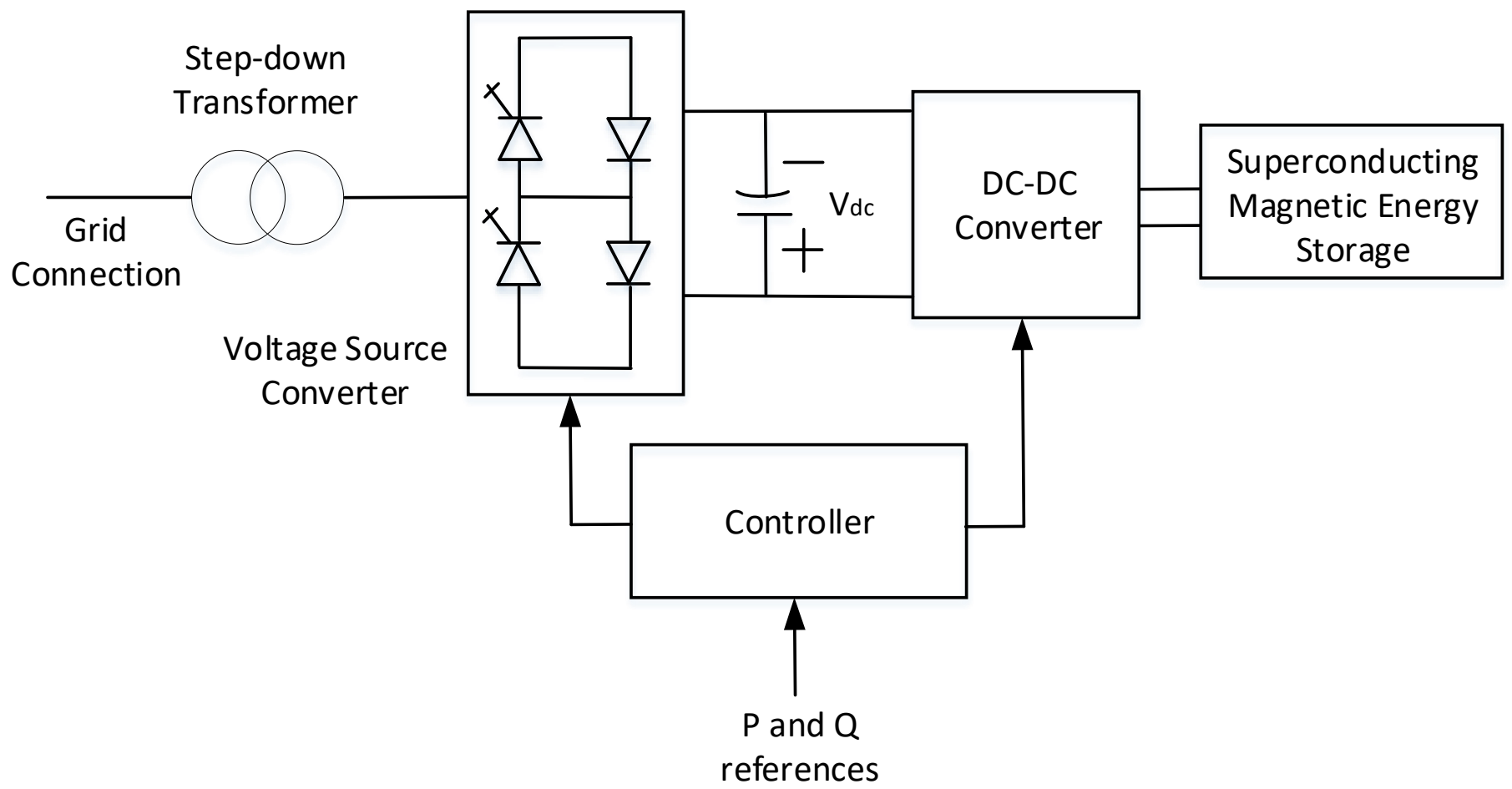

Figure 6. Block diagram representation of the static synchronous compensator.

4. Connection, Interaction, and Coordination among Nuclear Power Plant, Grid, and Protection Systems

\subsection{Connection}

For reliable and secure operation of a nuclear power plant, the International Atomic Energy Agency (IAEA) guidelines suggest that at least two independent connections should be furnished between a nuclear power plant and the grid [36]. The first connection is to transfer the power from the nuclear plant generator to the grid via the generator transformer, whereas the second connection is to supply the nuclear plant via the station transformer in the absence of the first connection. The power output involves a double circuit overhead high-voltage line in addition to cable lines to reduce the risk of a breakdown in case of adverse weather. A nuclear power plant requires a highly stable and reliable grid supply for their auxiliaries and safety systems. The nuclear plant safety systems are provided from various sources such as generators, independent diesel generators, distribution grids, high voltage grids, and battery banks [37]. Usually, all the station auxiliaries are supplied via the unit transformers, or half of the auxiliaries is served from the unit transformers and the other half is served via the station transformer to avoid common cause failures. The generator transformers and station transformers can be connected to the same substation provided that there is sufficient separation between the two connections. Alternatively, they can be connected to separate substations operating at different voltages. For a reliable off-site supply, a sufficient number of transmission circuit connections from the substations to the rest of the transmission system are also required. Measures are also needed to ensure that the substations and transmission circuits are sufficiently robust to withstand extreme events and natural disasters.

\subsection{Interaction}

The performance of a nuclear power plant is influenced by the electric grid. A nuclear power plant needs to stay connected to the grid, even in the presence of disturbances. Severe frequency and voltage disturbances may gravely influence the availability, reliability, and operability of a nuclear plant in the short as well as in the long term [15]. A prolonged 
voltage reduction will result in amplification of the excitation current of the generator, which may lead to overheating and may potentially cause generator tripping. In the case of large load-loss in the grid, the grid voltage will change steeply and generators may become unstable or be tripped by $\mathrm{V} / \mathrm{Hz}$ relays. Thus, generators are supplied with an over-excitation limiter and protection system to avoid these issues [11]. During oversupply of active power in the grid, the grid frequency may increase, and this will lead to an over-frequency condition, which will further affect the pressure and temperature variations in a nuclear power plant. The over-frequency relay, the turbine power control system, and the turbine-governor system act to keep the frequency at an acceptable level. The grid can sustain an off-nominal frequency for a considerable period; however, this may have mounting effects on the nuclear plant. For instance, this condition may cause damage to the turbine blades due to resonance. These variations also affect the auxiliary equipment of a nuclear power plant. Thus, during a disturbance, factors such as allowable operatingtime and total-operating time play a significant role in warranting the secure and stable operation of a nuclear power plant $[15,37]$.

\subsection{Coordination}

For the sake of a safe and stable operation, especially during frequency and voltage disturbances, strategies such as generation reduction, under-voltage load-shedding, and graded load-shedding must be carefully planned. Recent nuclear plant data show that a significant unscheduled downtime is due to disturbances in the power system [11]. Malfunctions in the power system produce variation in the grid frequency and voltage, which may upset the performance of the nuclear plant auxiliaries and may trigger relative relays. The nuclear plant protection system generally includes under- and over-frequency protection, $\mathrm{V} / \mathrm{Hz}$ protection, under-voltage protection, a over-speed detection system, excitation system protection, reactor cooling cycle control, neutron flux control, thermal protection, and power swing-related protections. During events that cause a reduction in frequency, the under-frequency relays and load shed relays are one of the primary protectors for turbo-generators. The first trip of under-frequency relay results in a faster decline in system frequency. This may trigger the main pump under-speed relay and may trip the nuclear unit. During prolonged under-frequency conditions, the under-frequency relay may worsen active power shortage and triggers under-frequency load shed relays. The under-frequency protection system is employed to avert damage to the turbine. On the other hand, during events that cause the frequency to increase, the over-frequency relays, protect controllers, and generator trip relays should coordinate to control the overfrequency. Situations such as plant trip and cascaded load-shedding should be avoided. The coordination of excitation and protection systems also have a considerable effect on the dynamic voltage deviation as well as on the voltage stabilisation process. Over-excitation limiters, main pump relays, and under-voltage load shed relays are employed to maintain stable system voltage. Thus, steady and methodical coordination among nuclear plant, grid, auxiliary power subsystems, and protection systems is essential to implement operating strategies and emergency measures [11,37]. The alternating/direct current power supplies and distribution systems, instrumentation and control systems, and containment electrical penetration assemblies are class $1 \mathrm{E}$ electrical systems [38]. These systems are interfaced with the nuclear plant and with other systems. Table A1 in Appendix A mentions the standards employed by the protection system for these systems [39].

\section{Simulation Cases, Results, and Discussion}

Here, the behaviour of the nuclear power plant and different network variables is studied in the presence of single-phase and three-phase faults. The behaviour of the plant is also studied following a permanent load-loss event. Figure 7 shows the line diagram of an electric grid with two generators that have a total electrical power generation capacity of 7.2 GW. The nuclear power plant (M1) has a 1.2 GWe capacity, and the hydro power 
plant (M2) has a 6 GWe capacity. The values of the parameters of all components of the model are given in Table A2 of Appendix A.

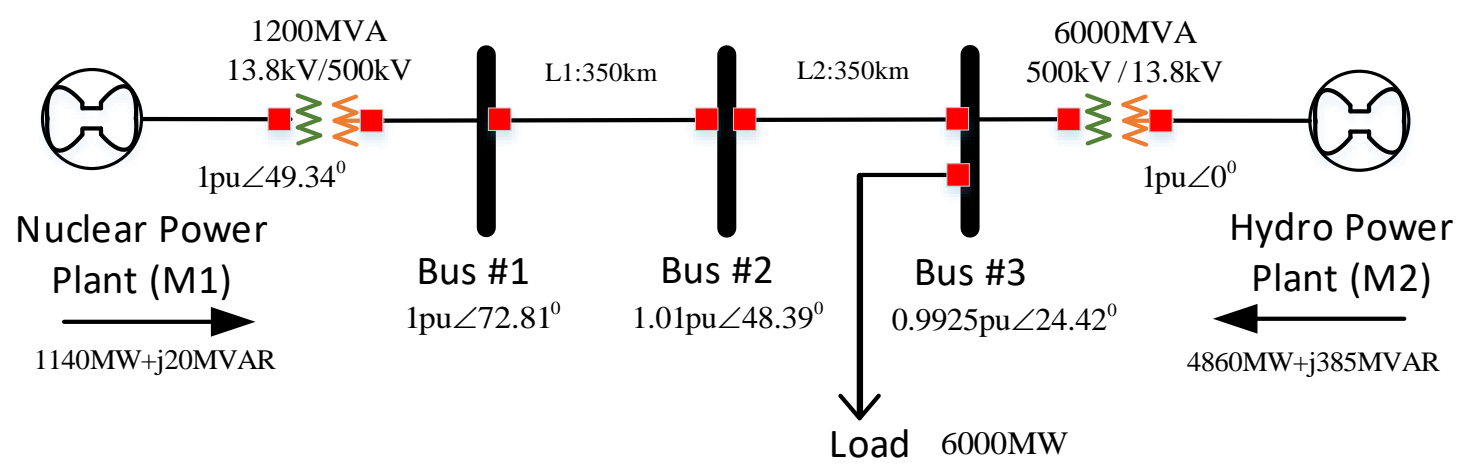

Figure 7. Network model of an electric grid.

\subsection{Case I: Response Under Single-Phase Fault}

A load-following operation of the nuclear plant is considered to analyse the system response in the presence of multiple single-phase faults. Here, three single-phase faults, each of $100 \mathrm{~ms}$ duration, is applied on bus 1 at $500 \mathrm{~s}, 900 \mathrm{~s}$, and $1200 \mathrm{~s}$. Initially, the nuclear power plant is run at $95 \%$ full power and the following power set-point sequence is considered:

$$
P_{n}^{r e f}= \begin{cases}0.95, & 0 \leq t \leq 200 \\ -0.0584(t-200) / 60+0.95, & 200<t \leq 700 \\ 0.4633, & 700<t \leq 1000 \\ 0.0584(t-700) / 60+0.4633, & 1000<t \leq 1500 \\ 0.95, & 1500<t \leq 2000\end{cases}
$$

The impact of faults on system stability is observed with generic PSS and multi-band PSS connected to the AVRs of M1 and M2. It is observed that the system becomes unstable in the absence of PSS. In the presence of PSS, the system stability can be analysed by assessing different network variables as shown in Figure 8. The rotor angle difference between the two plants is shown in Figure 8a. The rotor speeds of both plants are shown in Figure 8b. It can be noticed that, during the presence of fault, the speed of M1 rises as its electrical power is lower than its mechanical power. It can also be observed that there are oscillations present at a low frequency after fault clearing. The GPSS is able to damp the $0.8 \mathrm{~Hz}$ oscillations; however, it is not effective at damping the $0.025 \mathrm{~Hz}$ mode. The MBPSS can efficiently damp both the $0.8 \mathrm{~Hz}$ and the $0.025 \mathrm{~Hz}$ oscillations. The MBPSS rejects the fault disturbance earlier than the GPSS and has a lower settling time. The variation in terminal voltage and the voltage positive sequence are shown in Figure $8 c, d$, respectively. The variation in the mechanical power output of the nuclear plant and the control signal to the turbine-governor valve are illustrated in Figure 8e,f, respectively. It is observed that the turbine power output can follow the reference variations. Figure $8 \mathrm{~g}$, h show the variation in core neutronic power and total reactivity, respectively. The variation in other nuclear plant variables are given in Figure 9, in which Figure 9a depicts the fuel temperature, Figure $9 \mathrm{~b}$ shows the coolant temperature, Figure $9 \mathrm{c}$ shows the reactor plenum temperature, Figure $9 \mathrm{~d}$ shows the steam generator plenum temperature, Figure $9 \mathrm{e}$ shows the hot and cold leg temperatures, Figure $9 \mathrm{f}$ shows the PCL temperatures, Figure 9g shows the MTL temperatures, and Figure $9 \mathrm{~h}$ shows the pressuriser pressure. It has been observed that, in both cases, the system can handle multiple single-phase faults. The effect of faults on the plant side is suppressed by the PSS. The response of nuclear power plant variables shows that the GPSS gives oscillations after fault clearing. On the contrary, the MBPSS produces smooth variations in the plant signal and gives an oscillation-free response. 


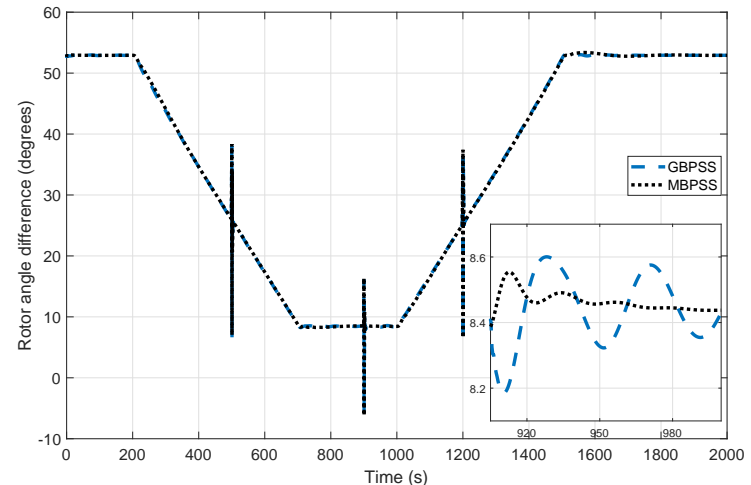

(a) Rotor angle difference.

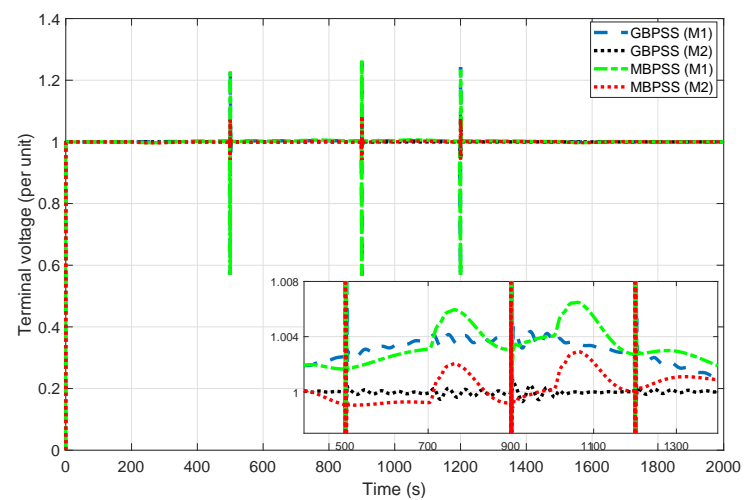

(c) Terminal voltage.

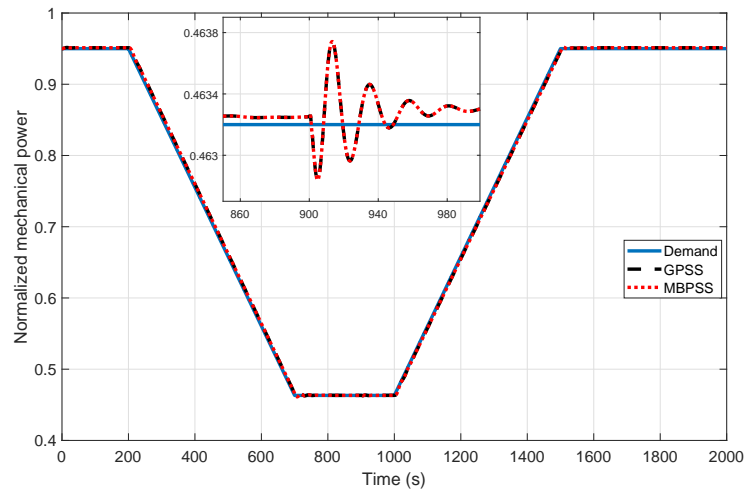

(e) Mechanical power of M1.

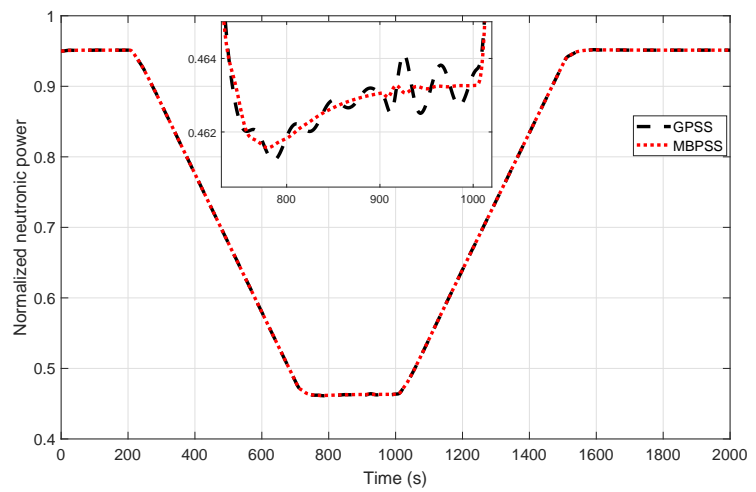

(g) Core neutronic power.

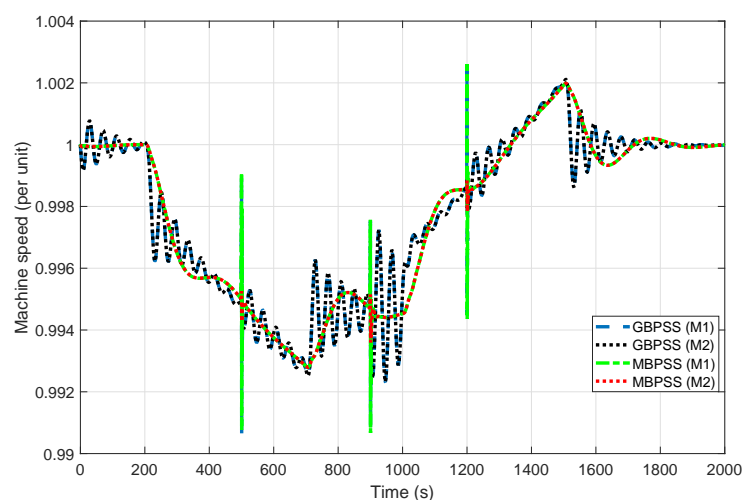

(b) Machine speed.

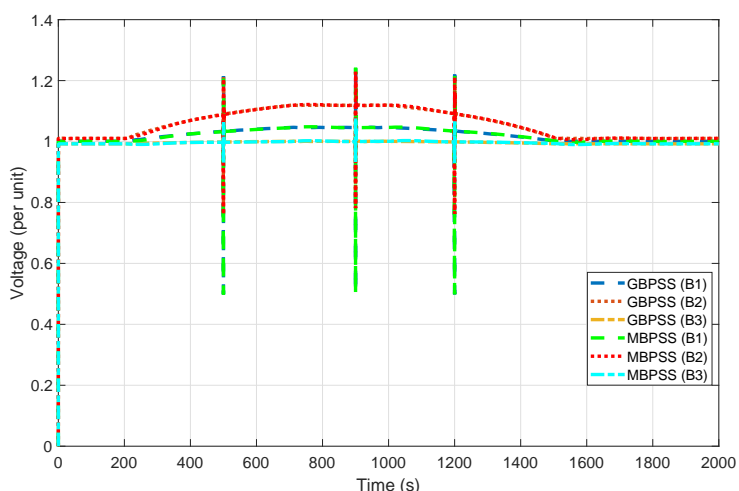

(d) Voltage positive sequence.

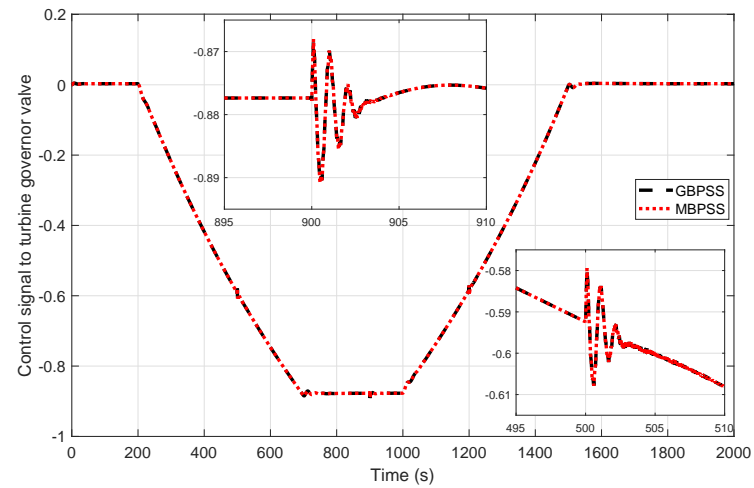

(f) Control signal to turbine governor valve.

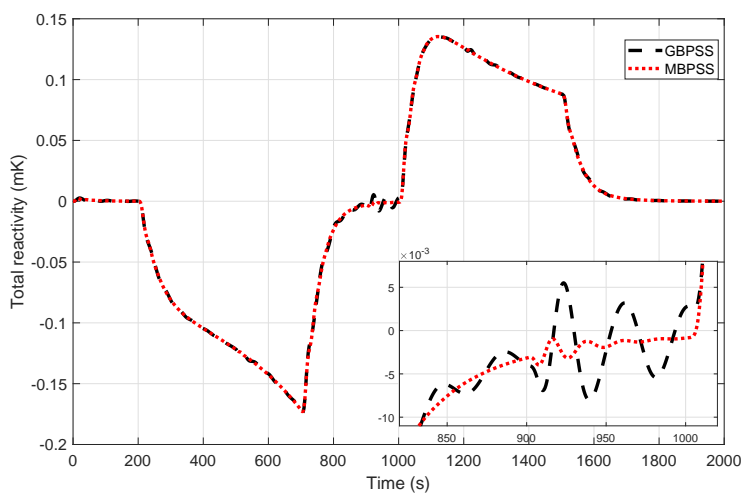

(h) Total reactivity.

Figure 8. Case I: Variation in network signals during single-phase faults with generic and multiband PSS. 


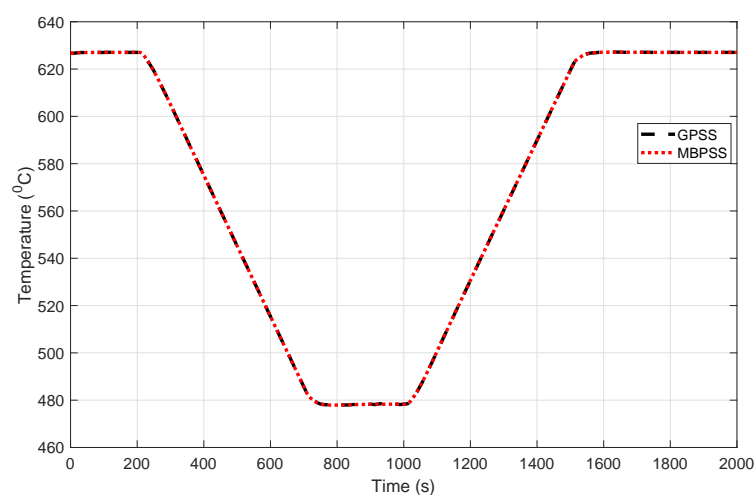

(a) Fuel temperature.

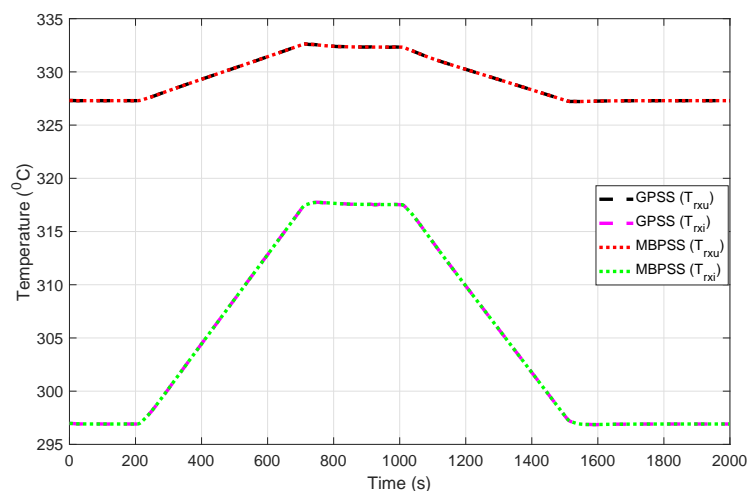

(c) Reactor plenum temperature.

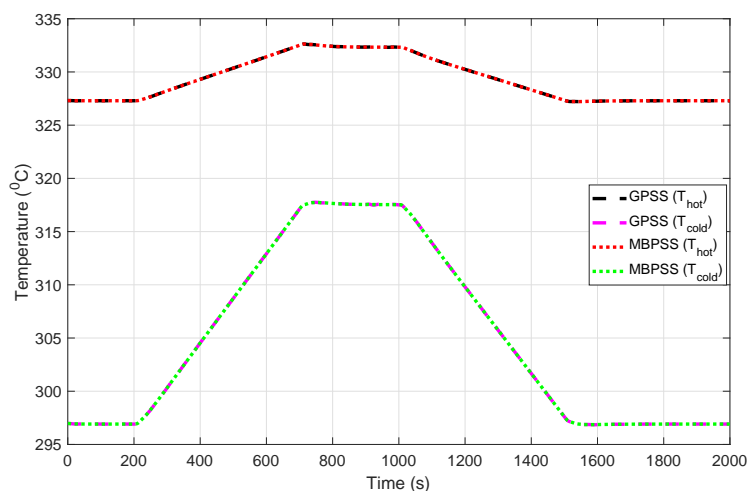

(e) Hot and cold leg temperature.

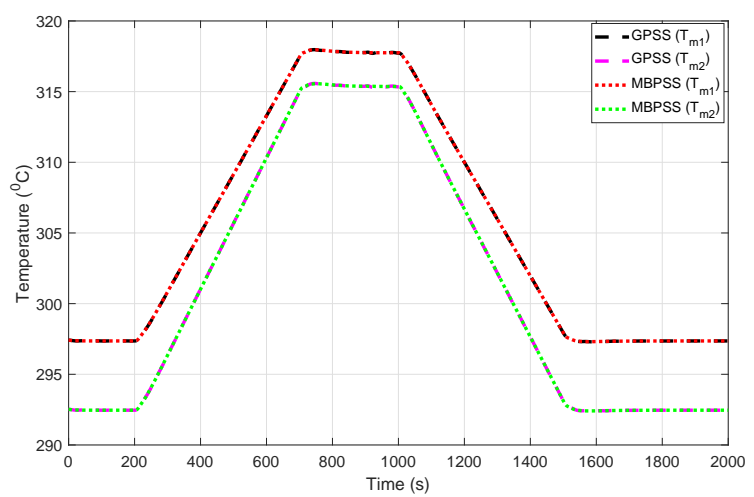

(g) Metal tube lump temperature.

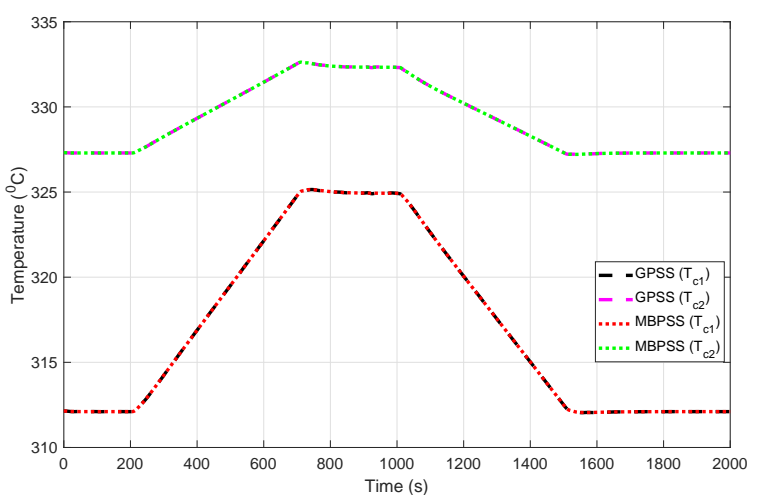

(b) Coolant temperature.

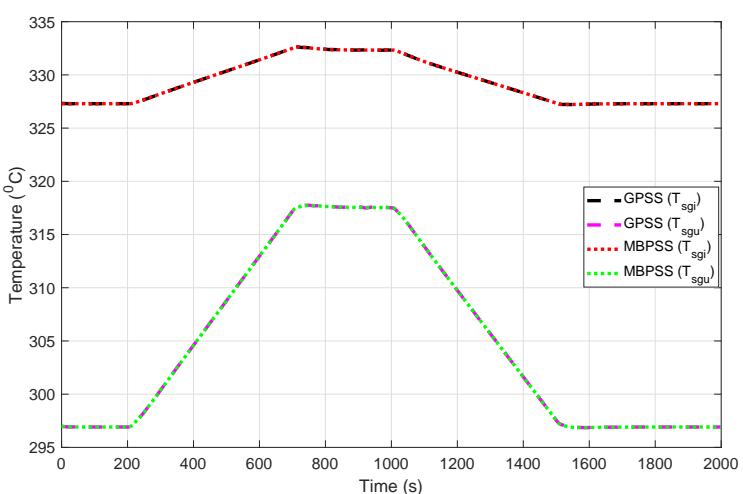

(d) Steam generator plenum temperature.

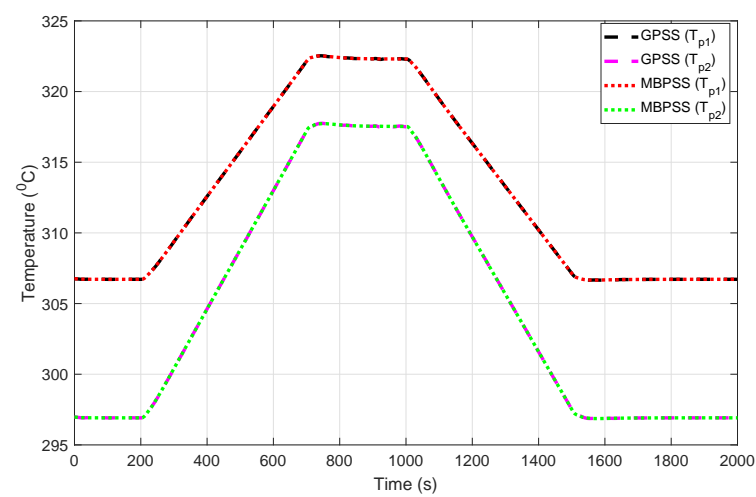

(f) Primary coolant lump temperature.

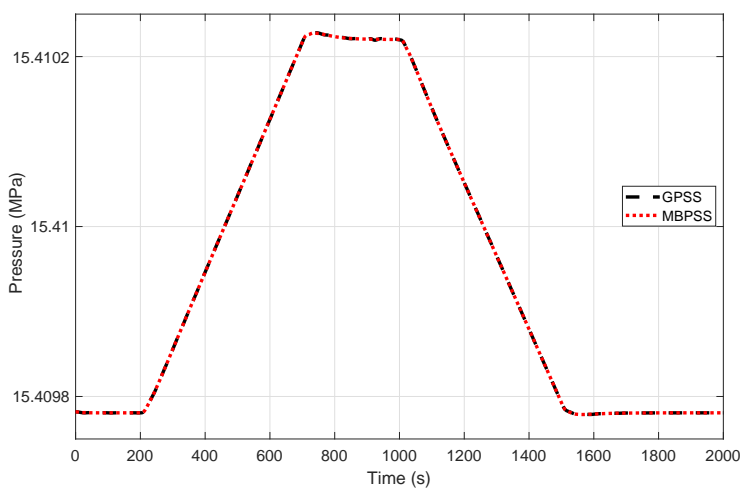

(h) Pressuriser pressure.

Figure 9. Case I: Variation in nuclear power plant variables following single-phase faults with generic and multiband PSS. 


\subsection{Case II: Response Under Three-Phase Fault}

In this section, the responses of the network and the plant variables are studied in the presence of three-phase faults. Here, four three-phase faults, each of $100 \mathrm{~ms}$ duration, are applied on bus 1 at $200 \mathrm{~s}, 500 \mathrm{~s}, 1000 \mathrm{~s}$, and $1500 \mathrm{~s}$. To study the response of the plant for a sudden variation in the load, a large ramp variation in the load is applied. This type of sudden load decrement transient reflects a restart after a shutdown scenario. The nuclear power plant is run at $95 \%$ full power, and the transient is given as follows:

$$
P_{n}^{r e f}= \begin{cases}0.95, & 0 \leq t \leq 220 \\ -1.608(t-220) / 60+0.95, & 220<t \leq 250 \\ 0.146, & 250<t \leq 800 \\ 0.05856(t-800) / 60+0.146, & 800<t \leq 1200 \\ 0.5364, & 1200<t \leq 1400 \\ 0.05856(t-1400) / 60+0.5364, & 1400<t \leq 1800 \\ 0.95, & 1800<t \leq 2000\end{cases}
$$

The impact of faults on system stability is first analysed for the case with a PSS at each generator but without FACTS compensation. It is observed from the rotor angle difference signal that the two machines quickly fall out of synchronism after fault clearing even in the presence of GPSS or MBPSS. The PSS alone is unable to keep the machines in sync. To mitigate this, a FACTS device is included in addition to the PSS at each generator to stabilise the network in the event of a three-phase fault contingency.

\subsubsection{PSS and SVC}

In this case, the transmission line is shunt compensated at bus 2 by an SVC. During the steady-state condition of the system, the reference voltage is manipulated per the load flow value of the bus voltage. Any variance in the voltage signal is compensated by the SVC. If the voltage is lower than the reference voltage, then the SVC injects reactive power on the line. However, the action of an SVC does not affect the damping torque of the system. Figure 10 shows the impact of three-phase faults on system stability having PSSs coupled with AVRs of M1 and M2 along with the SVC connected at bus 2. Figure 10a illustrates the variation in rotor angle difference, Figure 10b shows the machine speeds, Figure 10c shows the variation of terminal voltage, Figure $10 \mathrm{~d}$ shows the voltage positive sequence, Figure 10e shows the SVC voltage, and Figure 10f shows the SVC susceptance. From the figures, it is observed that the case involving GPSS and an SVC produces large but damped oscillations with a frequency of $0.025 \mathrm{~Hz}$. The speeds of the system generation units also swing together with the $0.025 \mathrm{~Hz}$ oscillation after fault clearing. The power system for the case of GPSS and SVC could not damp low-frequency oscillation, whereas the system with MBPSS and SVC is able to damp the oscillations and produces a smoother response of the variables. The variation in the mechanical power output of the turbine and the control signal to the valve are given in Figure 10g,h, respectively. The PI controller output can track the reference variation in both cases. The variation of other plant variables are illustrated in Figure 11, in which Figure 11a depicts the change in core neutronic power, Figure 11b depicts the change in total reactivity, Figure 11c shows the fuel temperature, Figure 11d shows the coolant temperature, Figure 11e shows the hot and cold leg temperatures, Figure $11 \mathrm{f}$ shows the PCL temperatures, Figure 11g shows the MTL temperatures, and Figure $11 \mathrm{~h}$ shows the pressuriser pressure. It is observed from the results that the system involving SVC and PSS can handle multiple three-phase faults. However, the response of nuclear power plant variables in the cases of GPSS and SVC is unable to damp the oscillations after fault clearing, which may severely affect the performance of the plant during recurring fault conditions. On the contrary, the system involving MBPSS and SVC was able to damp the oscillations and produces smooth plant response. Thus, the combination of MBPSS and SVC is recommended to handle severe three-phase faults. 


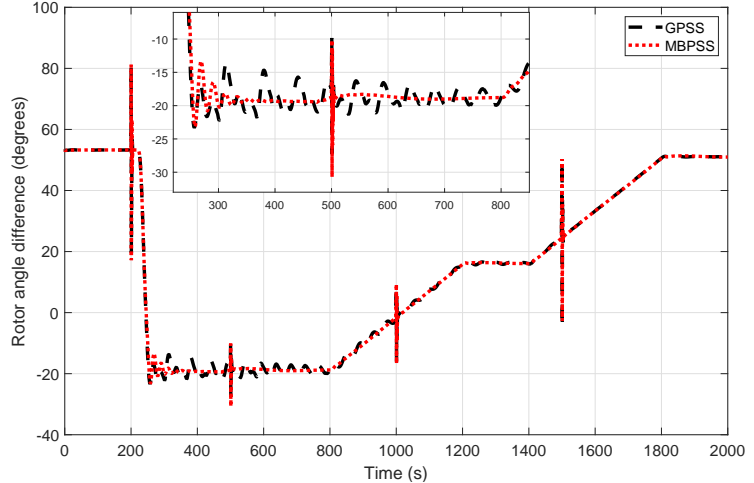

(a) Rotor angle difference.

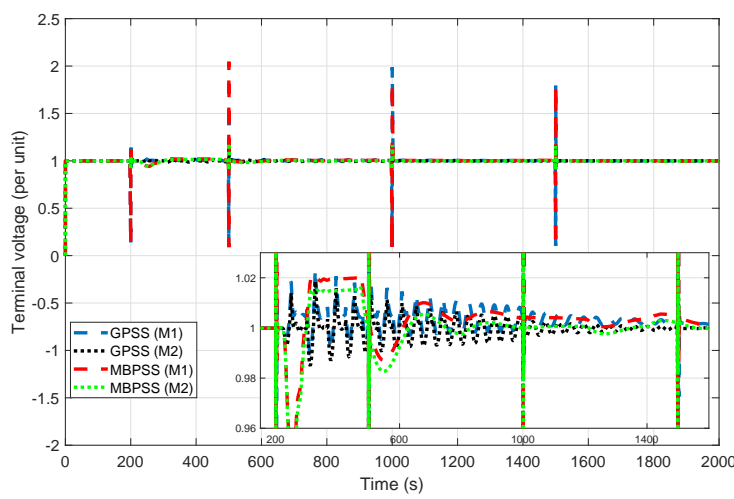

(c) Terminal voltage.

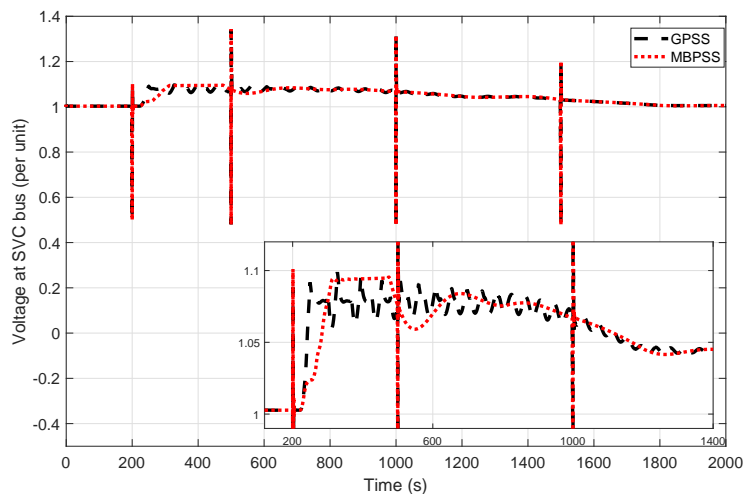

(e) SVC voltage.

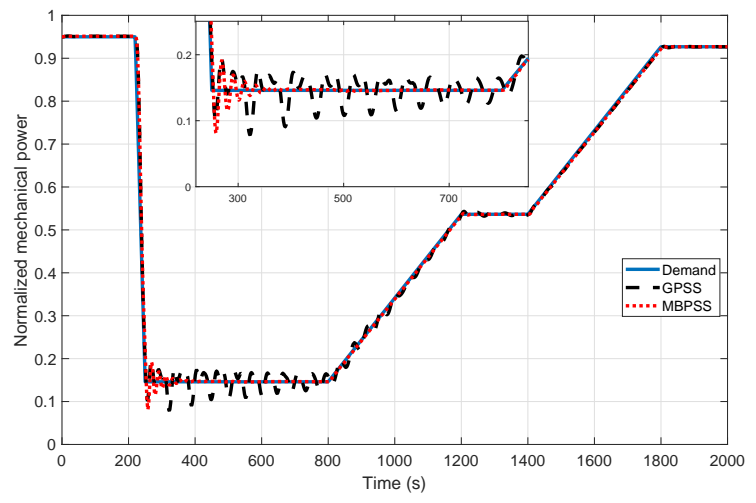

(g) Mechanical power.

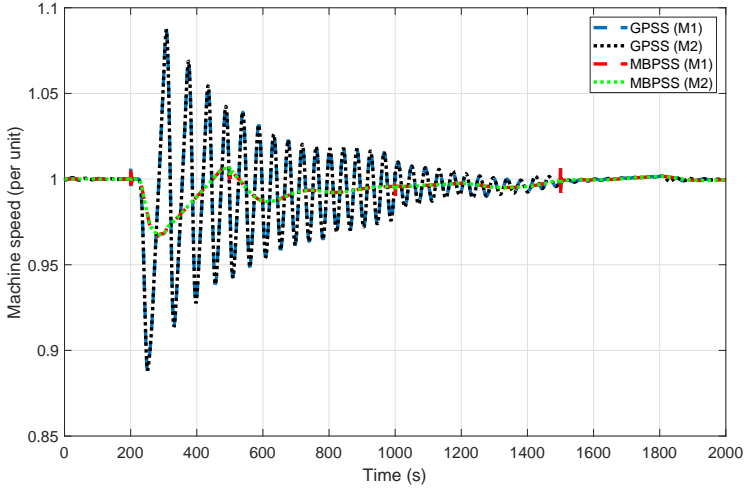

(b) Machine speed.

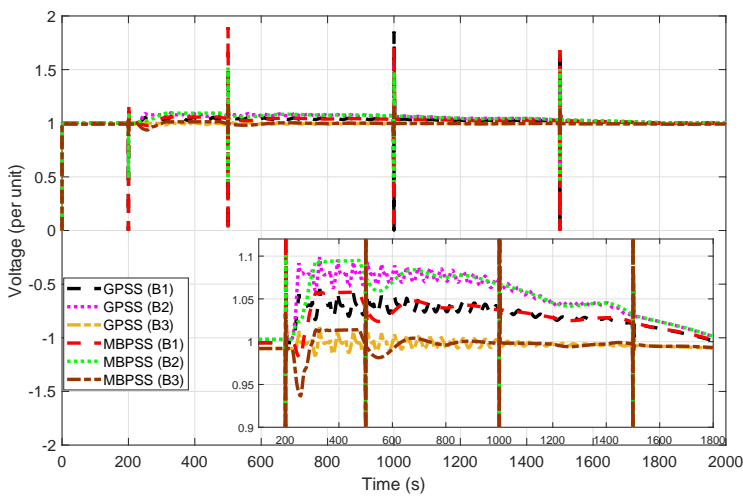

(d) Voltage positive sequence.

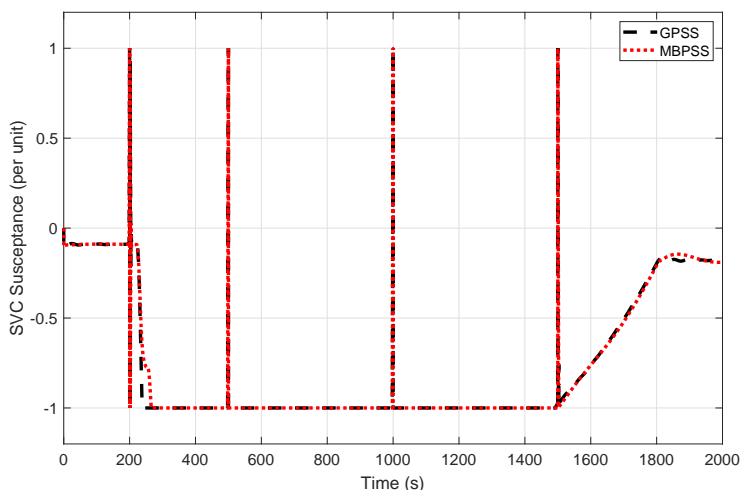

(f) SVC susceptance.

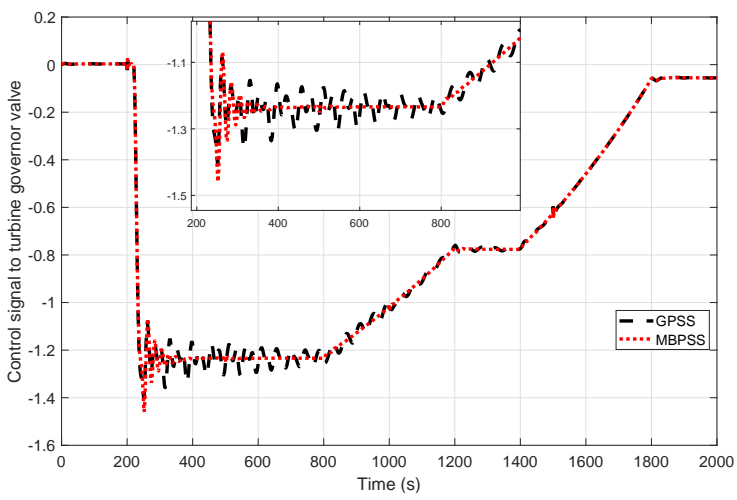

(h) Control signal to turbine governor valve.

Figure 10. Case II.1: Variation in network signals during three-phase faults with generic and multiband PSS with a static var compensator (SVC). 


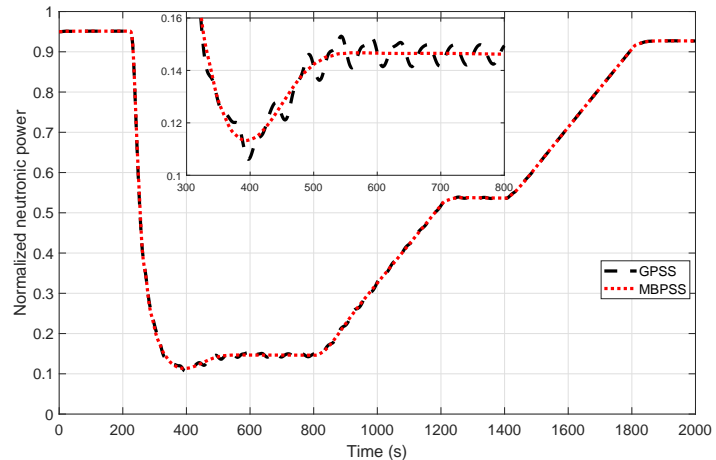

(a) Core neutronic power.

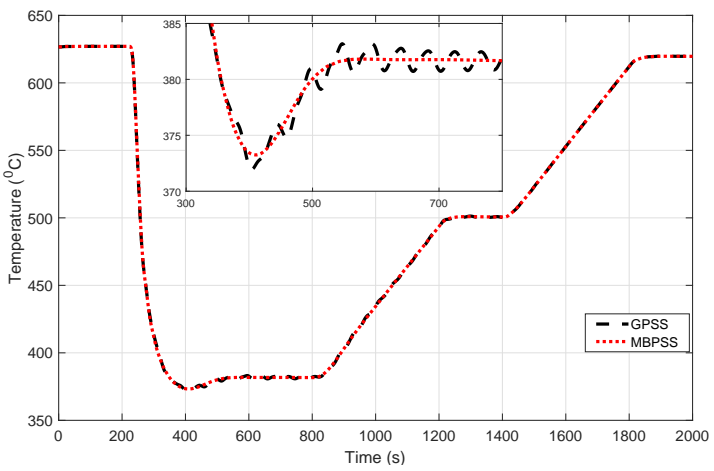

(c) Fuel temperature.

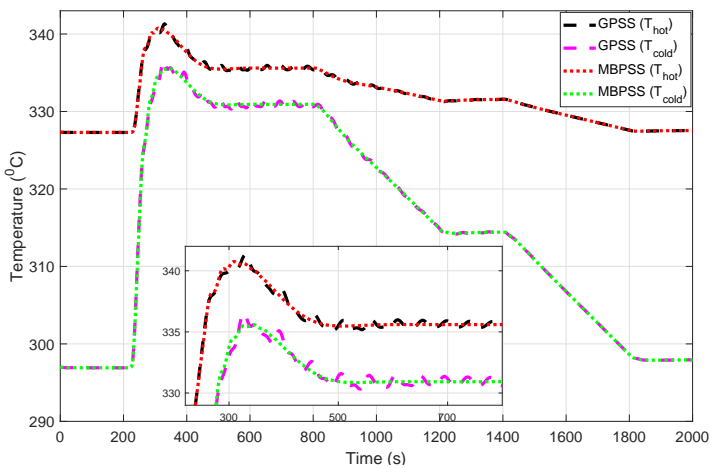

(e) Hot and cold leg temperature.

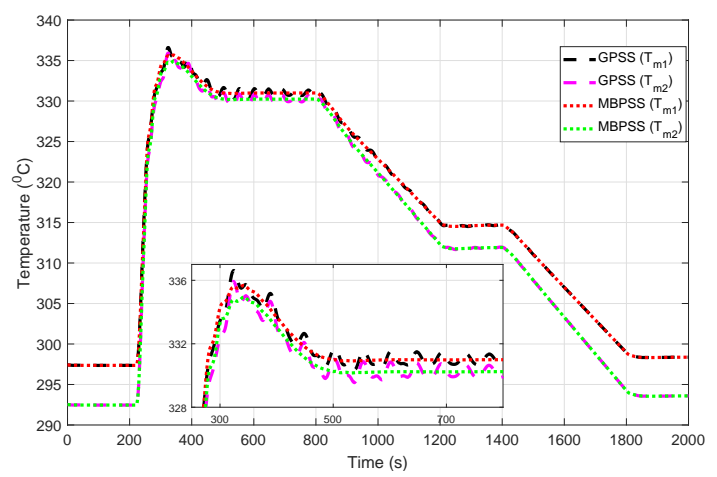

(g) Metal tube lump temperature.

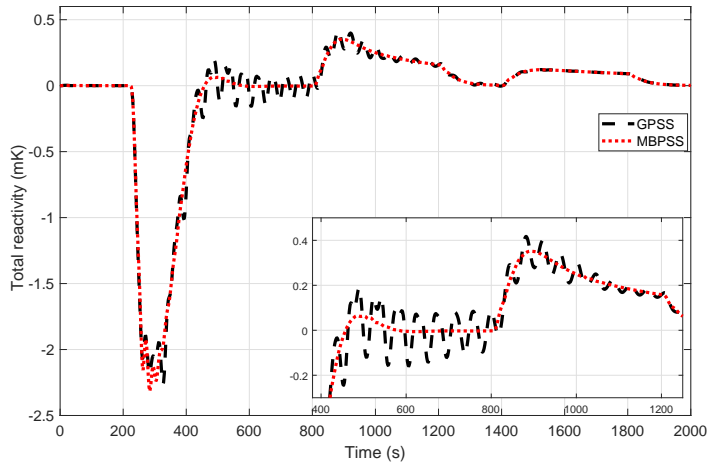

(b) Total reactivity.

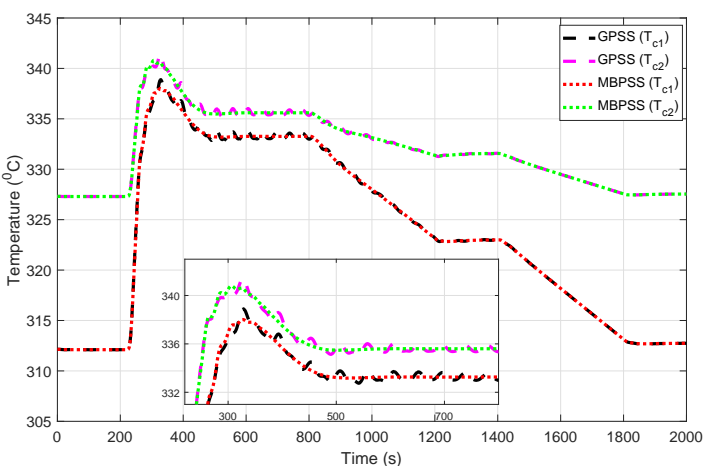

(d) Coolant temperature.

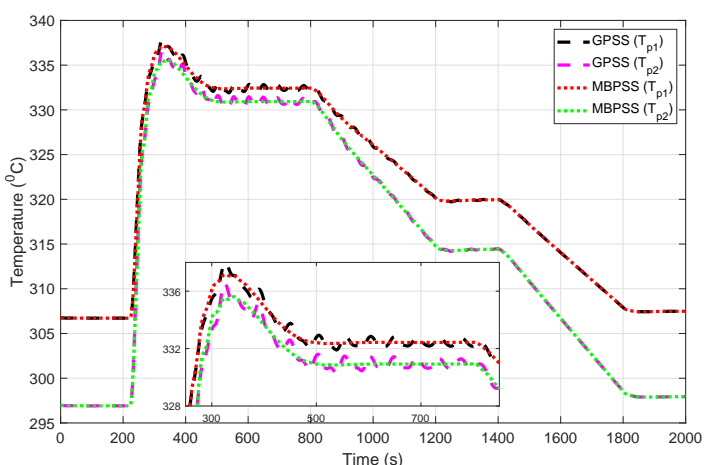

(f) Primary coolant lump temperature.

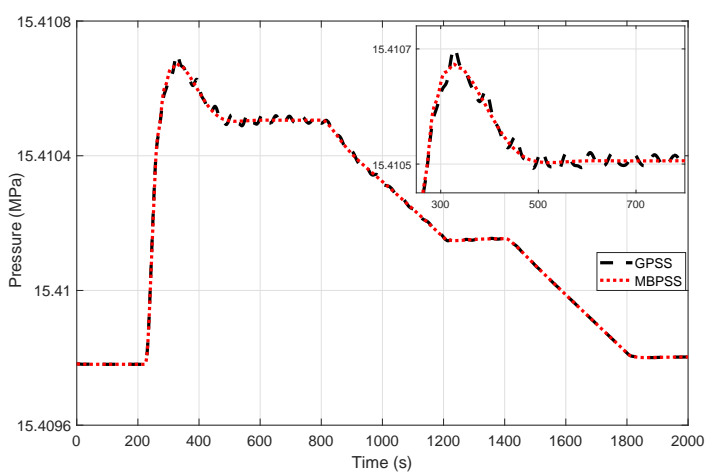

(h) Pressuriser pressure.

Figure 11. Case II.1: Variation in nuclear power plant variables following three-phase faults with generic and multiband PSS with SVC. 


\subsubsection{PSS and STATCOM}

In this case, the STATCOM is employed to test the efficacy of the coupling using PSSs at M1 and M2 and a shunt compensated FACTS device at bus 2. The impact of three-phase faults on system stability is studied for case involving GPSS and STATCOM, and MBPSS and STATCOM, as demonstrated in Figure 12. Figure 12a depicts the variation in rotor angle difference, Figure $12 \mathrm{~b}$ shows the machine speeds, Figure $12 \mathrm{c}$ shows the variation in terminal voltage, Figure $12 \mathrm{~d}$ shows the voltage positive sequence, Figure 12e shows the STATCOM voltage, and Figure $12 \mathrm{f}$ shows the STATCOM susceptance. It can be noted that the case involving GPSS and STATCOM is unable to damp the $0.025 \mathrm{~Hz}$ oscillations after fault clearing. On the other hand, the MBPSS and STATCOM combination can damp the oscillations and produces a smooth response. The variation in mechanical power output of the nuclear power plant and the control signal to the valve are shown in Figure 12g,h, respectively. The output of the turbine PI controller is steadily able to follow the reference variation in both cases. The variation in other plant variables are shown in Figure 13, in which Figure 13a depicts the variation of core neutronic power, Figure 13b shows the variation in total reactivity, Figure 13c shows the fuel temperature, Figure 13d shows the coolant temperature, Figure 13e shows the hot and cold leg temperatures, Figure $13 \mathrm{f}$ shows the PCL temperatures, Figure 13g shows the MTL temperatures, and Figure $13 \mathrm{~h}$ shows the pressuriser pressure. The response of various nuclear power plant variables when GPSS and STATCOM operate cannot fully damp the oscillations after fault clearing. Contrarily, the MBPSS and STATCOM system can damp the oscillations and produces smooth plant response. It can be noted from the figures that the system with STATCOM and PSS can handle multiple three-phase faults better than the SVC with the PSS system. The STATCOM-based system can also damp the oscillations better than that of the SVC-based system. In case of a STATCOM, the maximum capacitive power reduces linearly with voltage decrease due to a constant current, whereas in the case of an SVC, it is proportional to the square of the system voltage due to constant susceptance. Thus, the STATCOM can provide more capacitive power during a fault as compared to the SVC.

\subsection{Case III: Response Under Permanent Load Loss}

In this section, the responses of the network and the plant variables are studied during a permanent load-loss from the electric grid. Initially, the hydro power plant (M2) was run at $81 \%$ full-power. At $t=500 \mathrm{~s}$, a permanent load-loss at bus 3 of $1800 \mathrm{MW}$ was considered, which caused the hydro-power plant to decrease the power output to a steady-state value of $51 \%$. The impact of the permanent load-loss on system stability was studied in the case with PSSs at M1 and M2 and a shunt FACTS device connected to bus 2. Similar to the three-phase fault case, the two machines fall out of synchronism if no shunt FACTS device is present. Thus, a shunt FACTS device was incorporated at bus 2 to keep the network stable during the load-loss transient. Here, an SVC and a STATCOM were considered as alternatives to stabilise the network during a permanent load-loss situation, together with PSS at M1 and M2. 


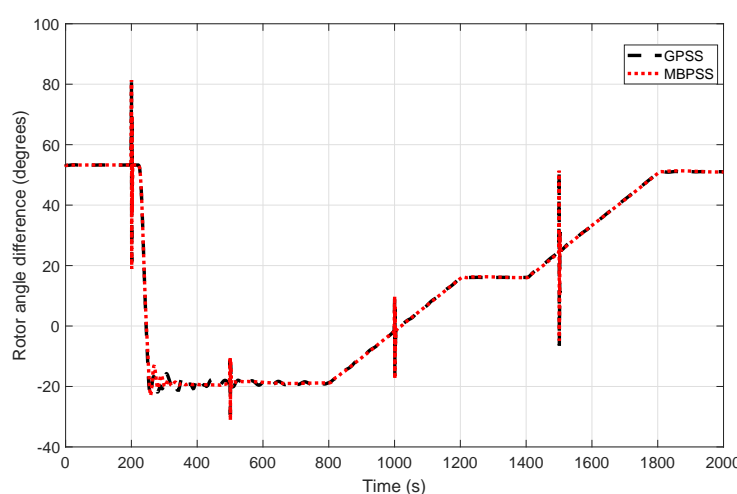

(a) Rotor angle difference.

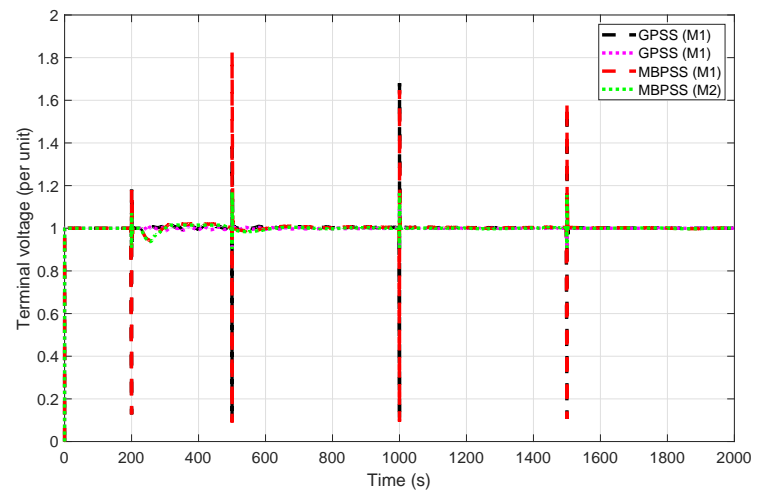

(c) Terminal voltage.

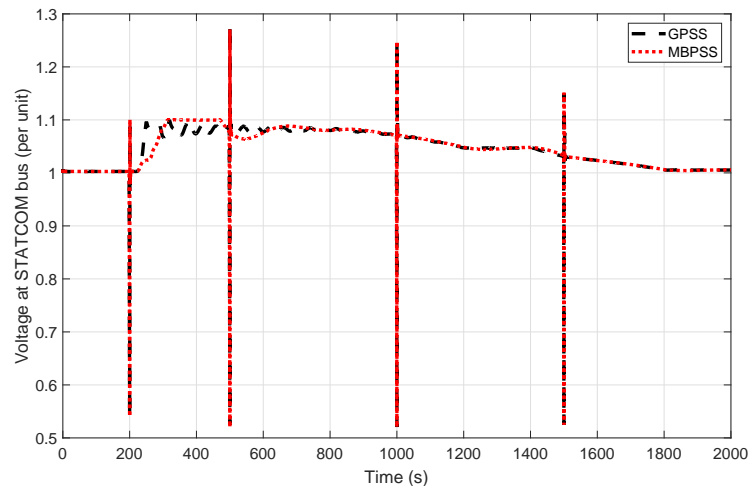

(e) STATCOM voltage.

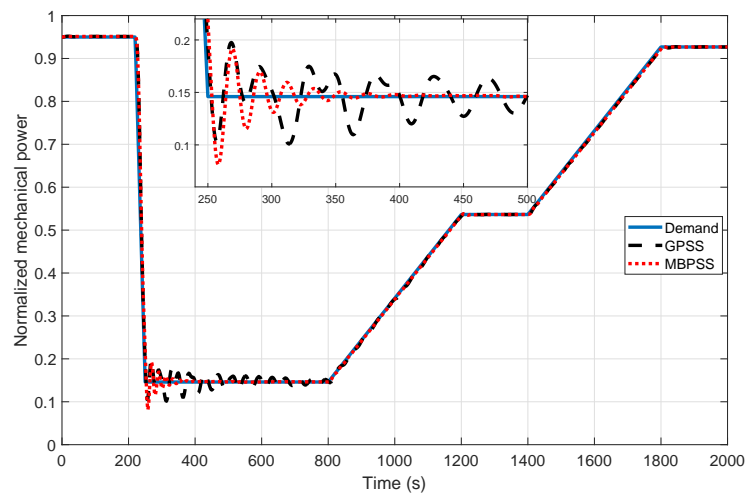

(g) Mechanical power.

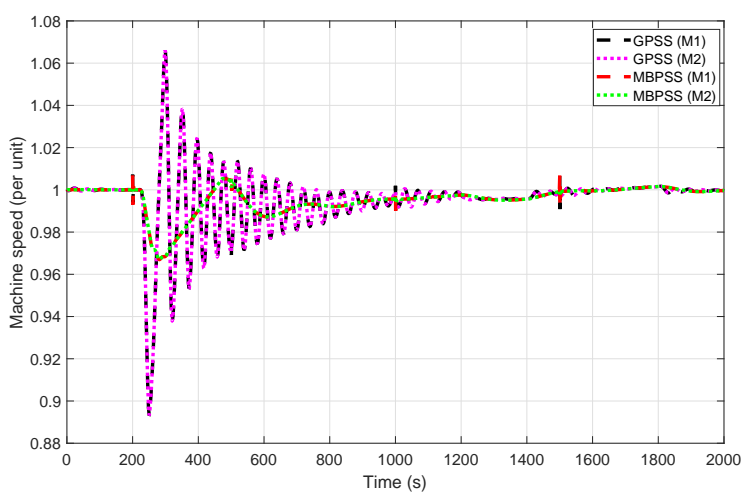

(b) Machine speed.

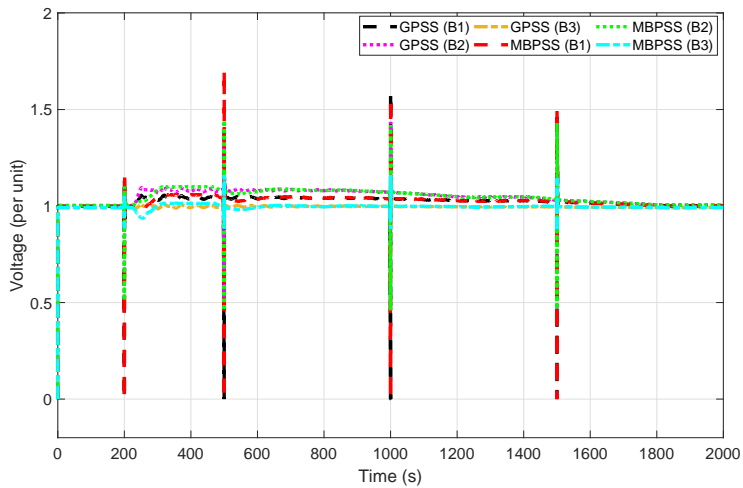

(d) Voltage positive sequence.

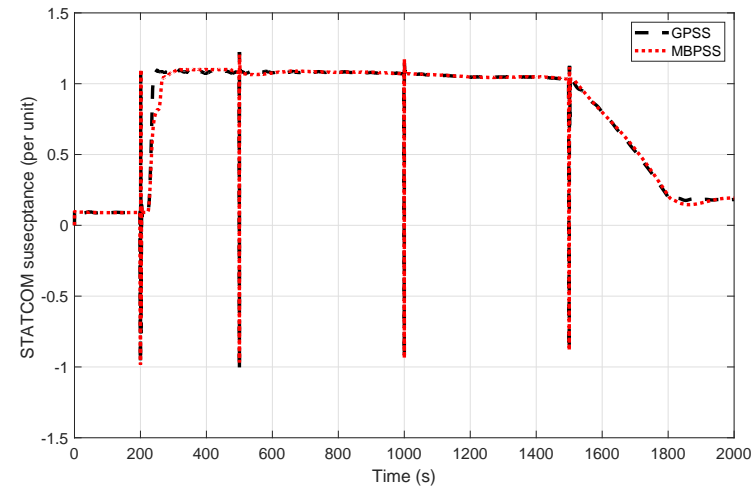

(f) STATCOM susceptance.

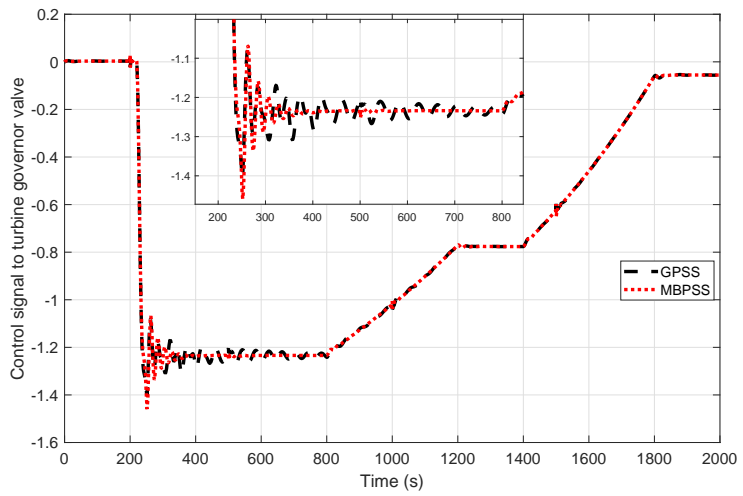

(h) Control signal to turbine governor valve.

Figure 12. Case II.2: Variation of network signals during three-phase faults with generic and multiband PSS with static synchronous compensator (STATCOM). 


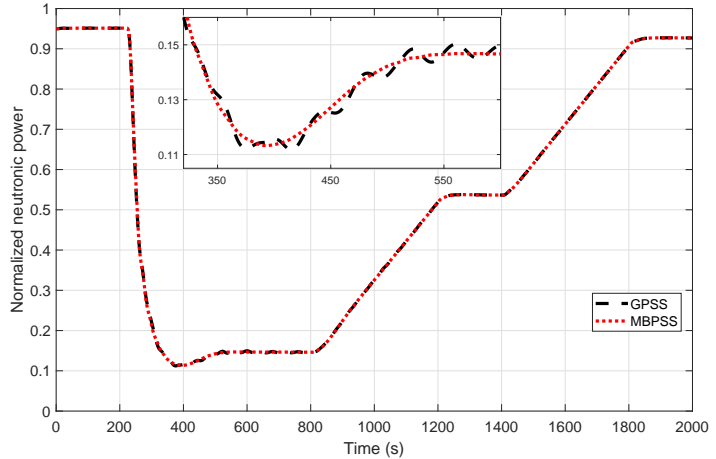

(a) Core neutronic power.

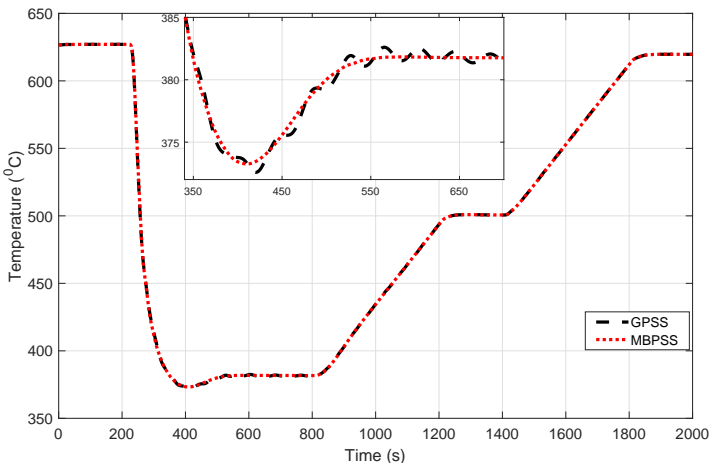

(c) Fuel temperature.

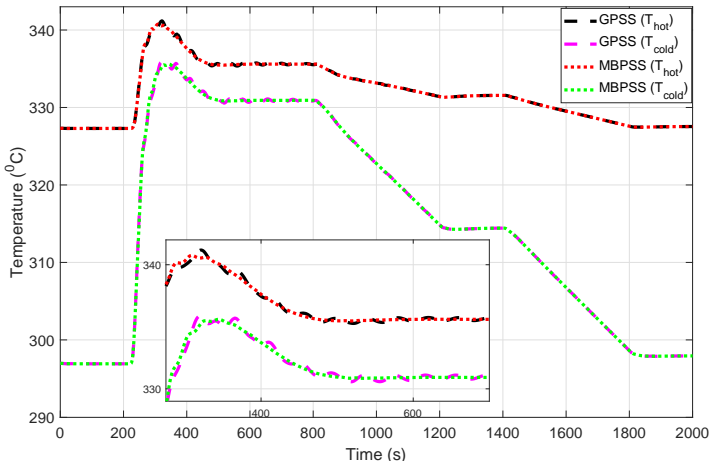

(e) Hot and cold leg temperature.

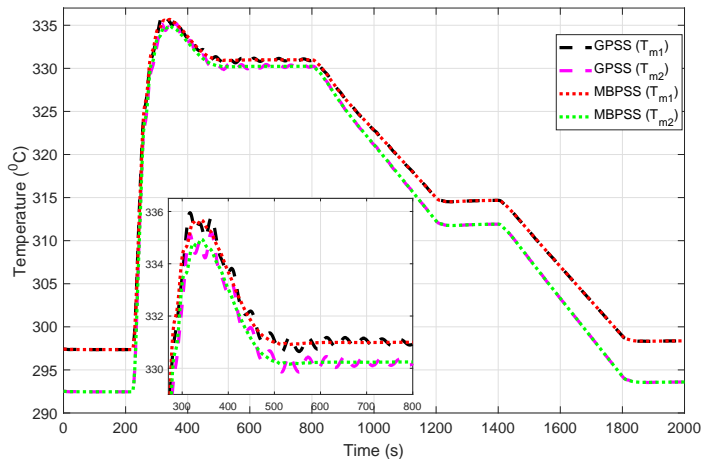

(g) Metal tube lump temperature.

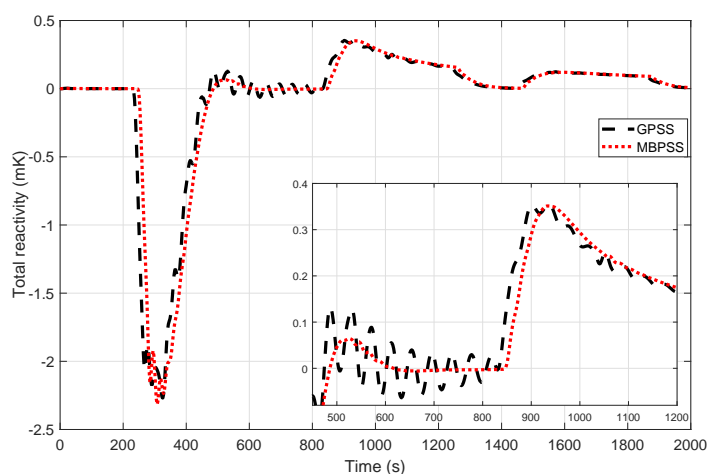

(b) Total reactivity.

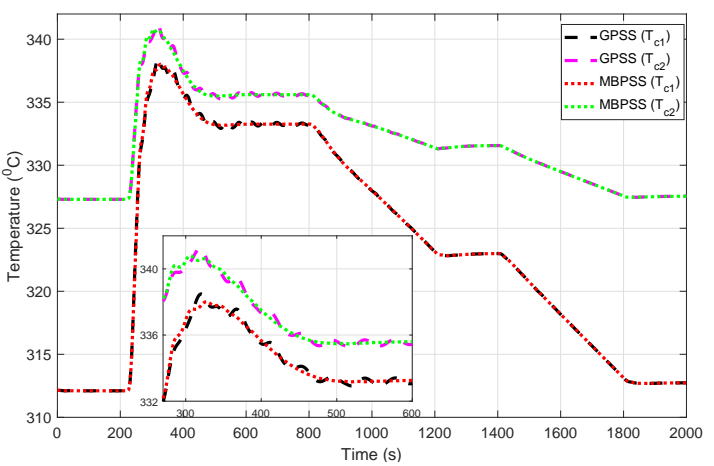

(d) Coolant temperature.

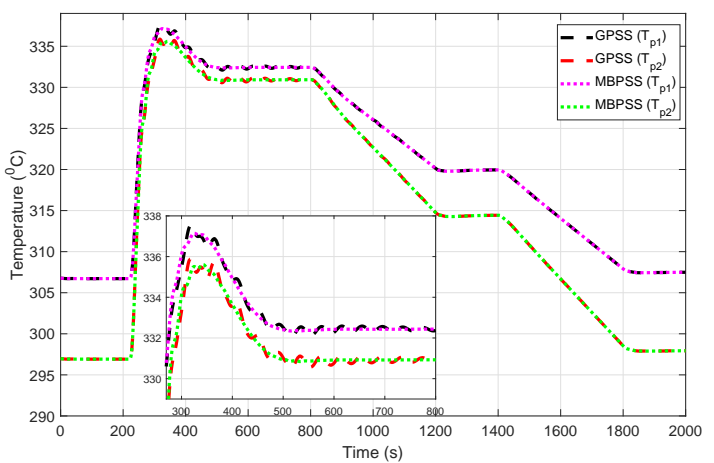

(f) Primary coolant lump temperature.

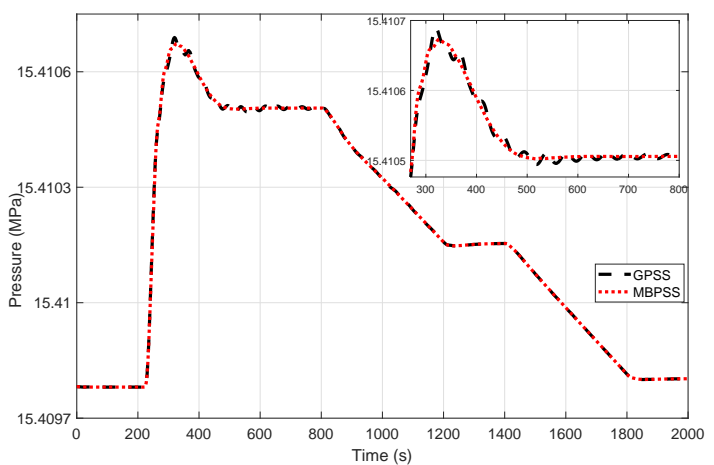

(h) Pressuriser pressure.

Figure 13. Case II.2: Variation of nuclear power plant variables during three-phase faults with generic and multiband PSS with STATCOM. 


\subsubsection{PSS and SVC}

The system stability was studied following a permanent load-loss event for the case with GPSS and MBPSS along with an SVC in operation, as demonstrated in Figure 14. Figure 14a shows the variation in rotor angle difference, Figure 14b shows the machine speeds, Figure 14c shows the variation in terminal voltage, Figure 14d shows the voltage positive sequence, Figure 14e shows the SVC voltage, and Figure 14f shows the SVC susceptance. The variation in mechanical power output of the HPP is shown in Figure 14g. The permanent load-loss transient at the electric grid reduces the power output at the HPP. The turbine speed controller at the HPP can handle the large permanent load-loss transient. The PI controller during the GPSS produces a $35.19 \%$ peak undershoot in the mechanical power output of the HPP, whereas the MBPSS produces a $26.54 \%$ peak undershoot. The variation in the mechanical power output of the turbine is shown in Figure 14h. The turbine speed controller at the nuclear plant can maintain a steady-state in both cases. Use of the GPSS results in a transient with \pm 11.48 variation in the mechanical power output of the nuclear plant, whereas the MBPSS results in a power variation within \pm 2.54 . Moreover, the MBPSS can damp the oscillations better than the GPSS. The variation in other plant variables are shown in Figure 15, in which Figure 15a depicts the change in core neutronic power, Figure $15 \mathrm{~b}$ depicts the change in the control signal to the valve, Figure $15 \mathrm{c}$ shows the total reactivity, Figure $15 \mathrm{~d}$ shows the fuel temperature, Figure $15 \mathrm{e}$ shows the coolant temperature, Figure $15 \mathrm{f}$ shows the hot and cold leg temperatures, Figure $15 \mathrm{~g}$ shows the PCL temperatures, and Figure 15h shows the MTL temperatures. From the figures, it can be observed that both the MBPSS with SVC and the GPSS with SVC can handle the permanent load loss situation at the nuclear power plant, in which the MBPSS-based system produces fewer variations in the nuclear power plant variables compared to the GPSS-based system.

\subsubsection{PSS and STATCOM}

In this case, the system stability following a permanent load-loss at bus 3 is studied for the case with PSS and STATCOM in operation, as demonstrated in Figure 16. Figure 16a depicts the change in rotor angle difference, Figure 16b shows the machine speeds, Figure 16c shows the variation of terminal voltage, Figure $16 \mathrm{~d}$ shows the voltage positive sequence, Figure 16e shows the STATCOM voltage, and Figure 16f shows the STATCOM susceptance. The variation in the mechanical power output of the HPP is shown in Figure 16g. The turbine speed controller at the HPP can handle the large permanent load-loss transient. The PI controller during the GPSS produces a $36.73 \%$ peak undershoot in the mechanical power of HPP, whereas the MBPSS produces a $26.21 \%$ peak undershoot. The variation in the mechanical power output of the nuclear plant is shown in Figure 16h. The turbine speed controller at the nuclear plant can maintain a steady state in both cases. Use of the GPSS results in a transient with \pm 11.43 variation in the mechanical power output of the nuclear plant, whereas use of the MBPSS results in a mechanical power variation within \pm 2.47 . In addition, the MBPSS can damp the oscillations better than the GPSS. The variation in other nuclear plant variables are shown in Figure 17, in which Figure 17a shows the variation in core neutronic power, Figure 17b depicts the change in the control signal to the valve, Figure $17 \mathrm{c}$ shows the total reactivity, Figure $17 \mathrm{~d}$ shows the fuel temperature, Figure $17 \mathrm{e}$ shows the coolant temperature, Figure $17 \mathrm{f}$ shows the hot and cold leg temperatures, Figure $17 \mathrm{~g}$ shows the PCL temperatures, and Figure 17h shows the MTL temperatures. From the figures, it can be noted that the MBPSS and STATCOM produce fewer variations in the nuclear power plant variables compared to the GPSS and STATCOM. The STATCOM-based system works better than the SVC-based system as the STATCOM can impart more reactive power during a fault compared to the SVC and exhibits a swift response than the SVC. 


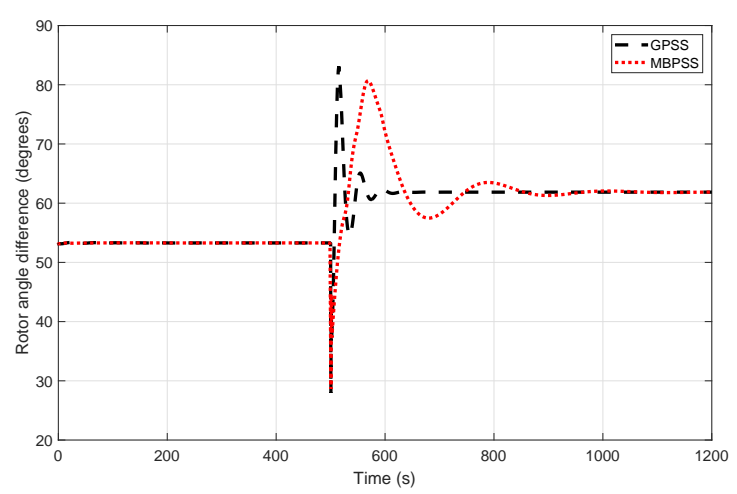

(a) Rotor angle difference.

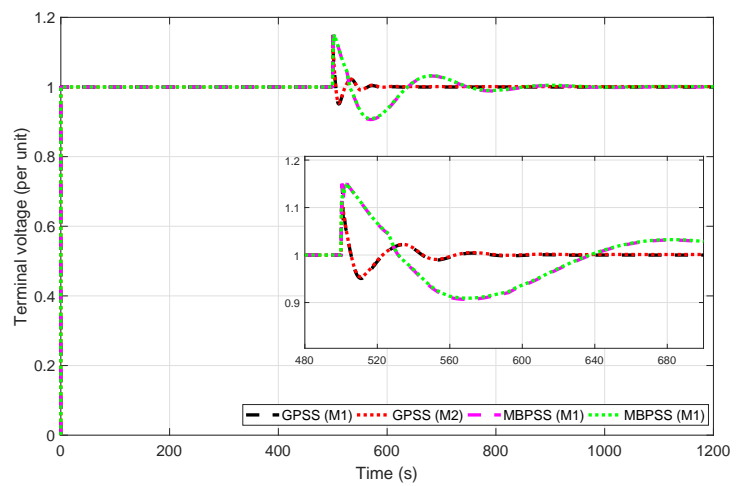

(c) Terminal voltage.

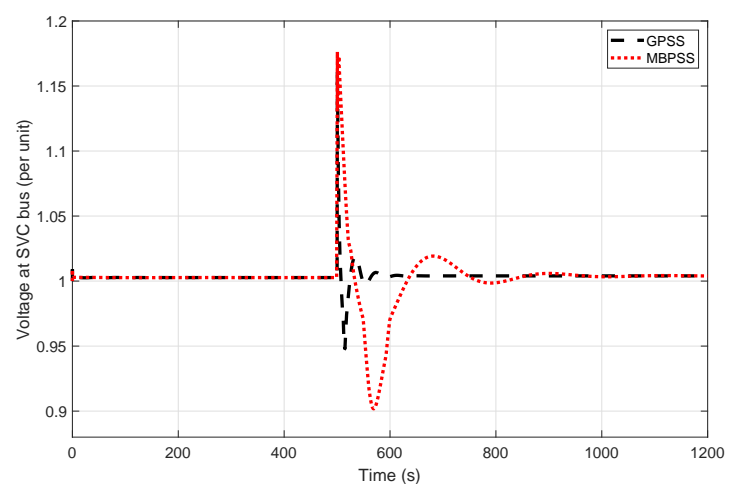

(e) SVC voltage.

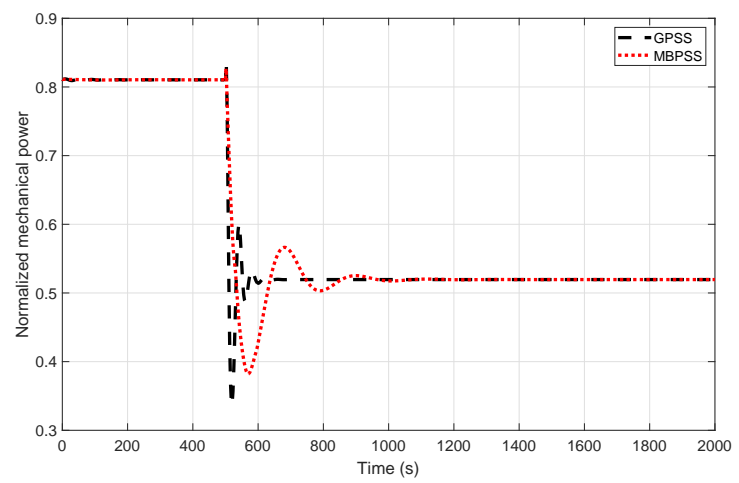

(g) Mechanical power of M2.

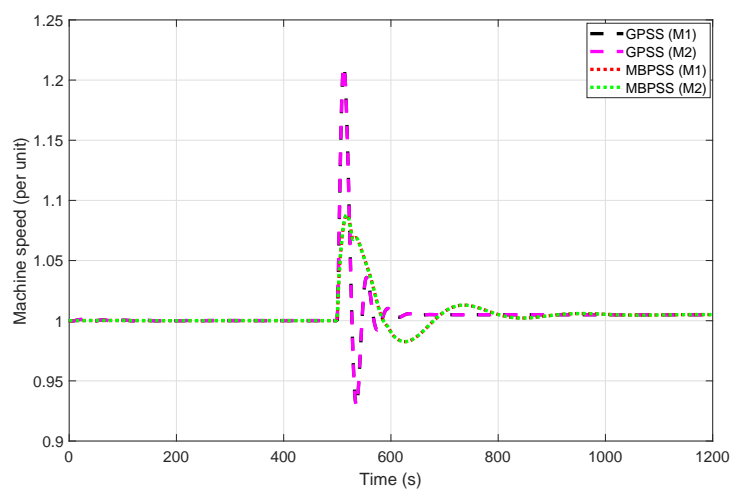

(b) Machine speed.

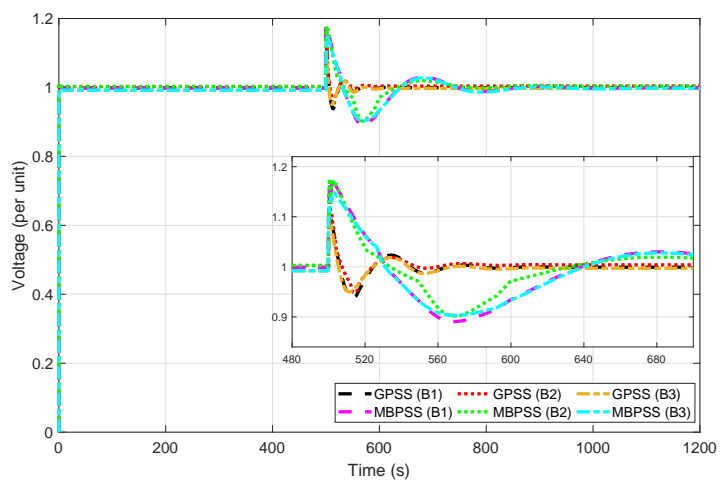

(d) Voltage positive sequence.

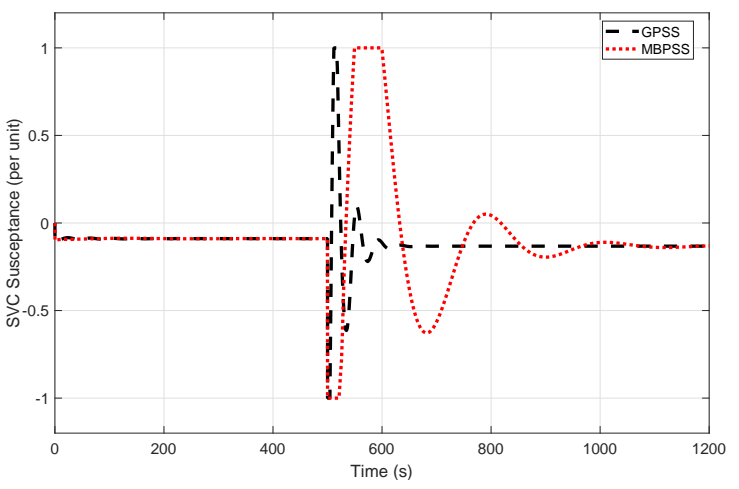

(f) SVC susceptance.

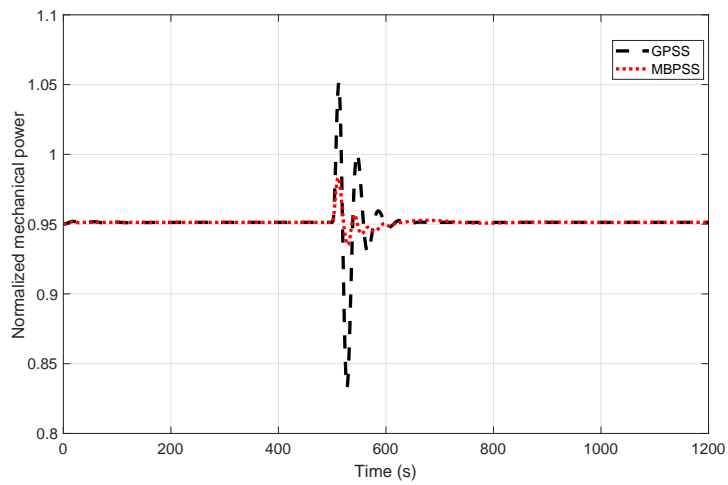

(h) Mechanical power of M1.

Figure 14. Case III.1: Variation in network signals during permanent load loss with generic and multiband PSS with SVC. 


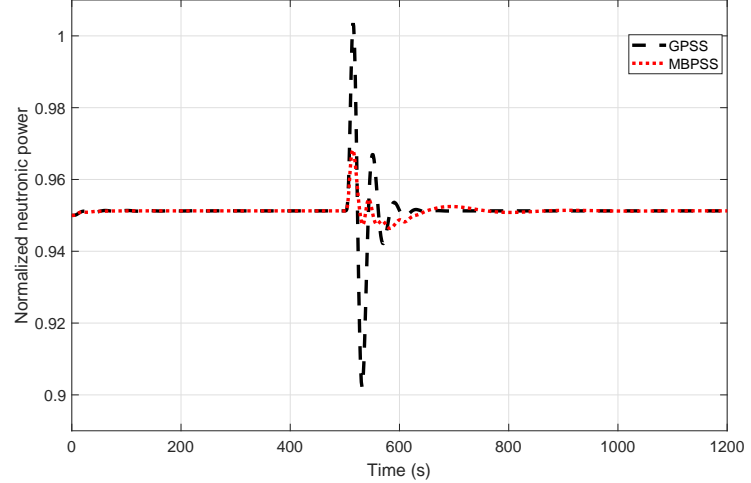

(a) Core neutronic power.

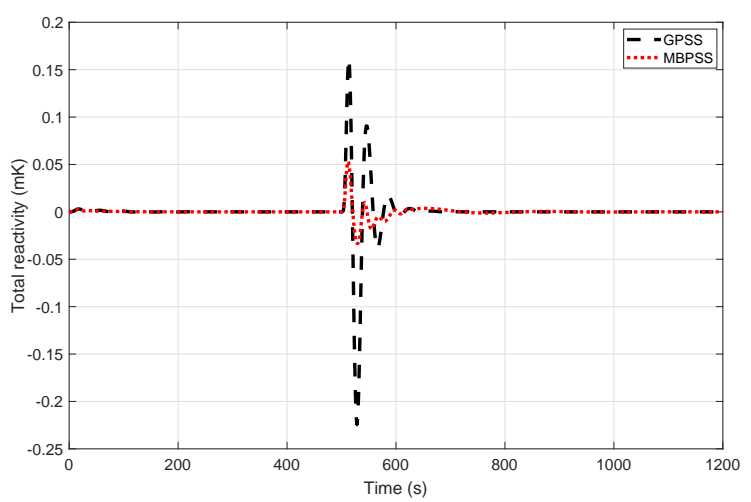

(c) Total reactivity.

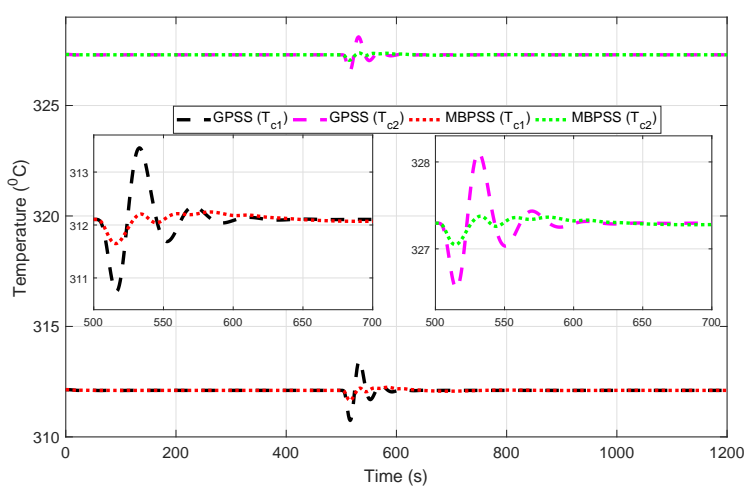

(e) Coolant temperature.

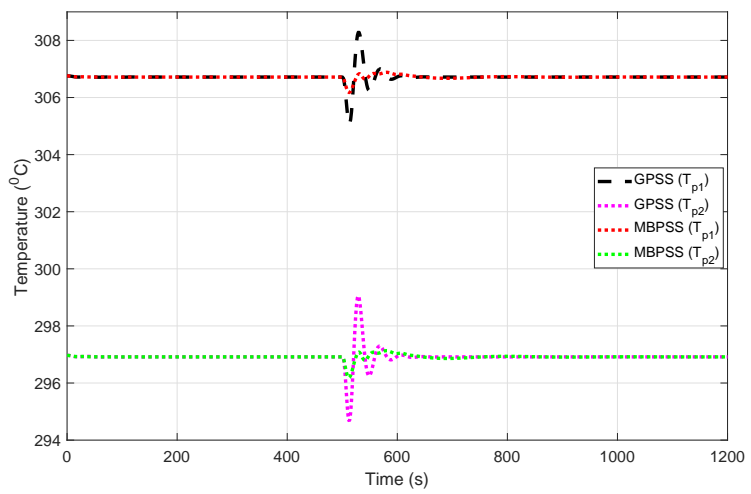

(g) Primary coolant lump temperature.

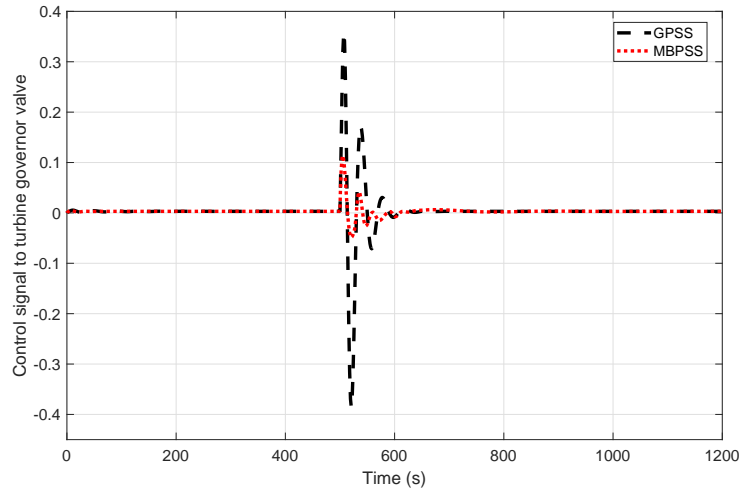

(b) Control signal to turbine governor valve.

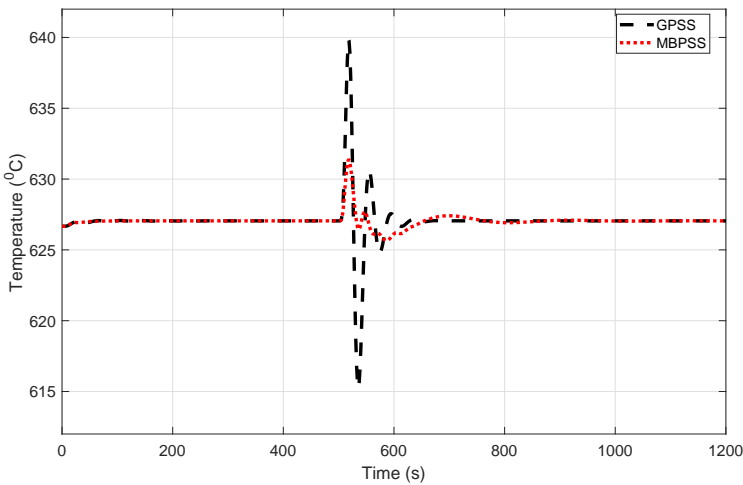

(d) Fuel temperature.

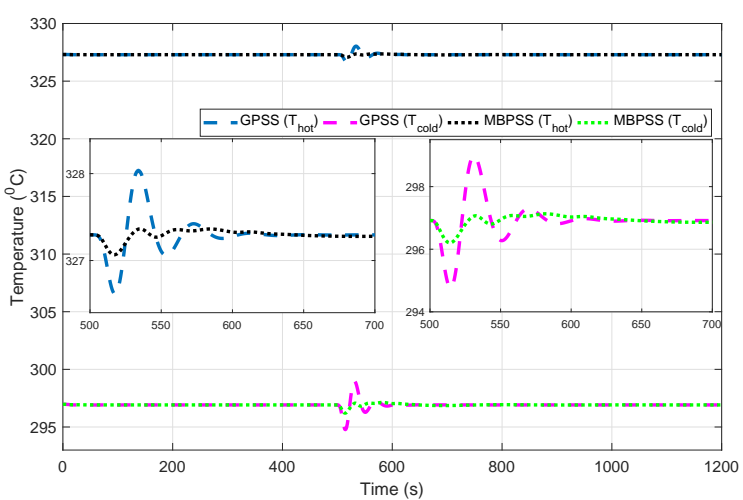

(f) Hot and cold leg temperature.

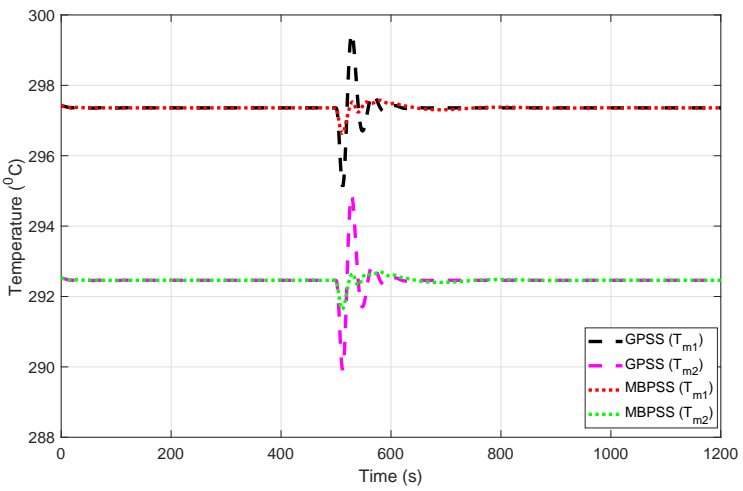

(h) Metal tube lump temperature.

Figure 15. Case III.1: Variation in nuclear power plant variables during permanent load loss with generic and multiband PSS with SVC. 


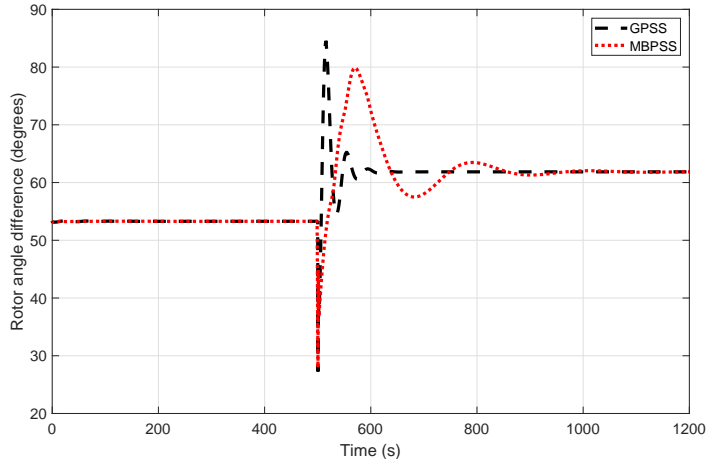

(a) Rotor angle difference.

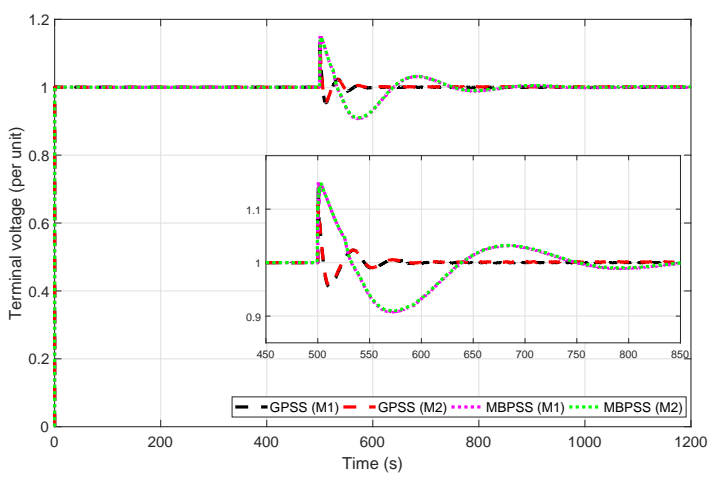

(c) Terminal voltage.

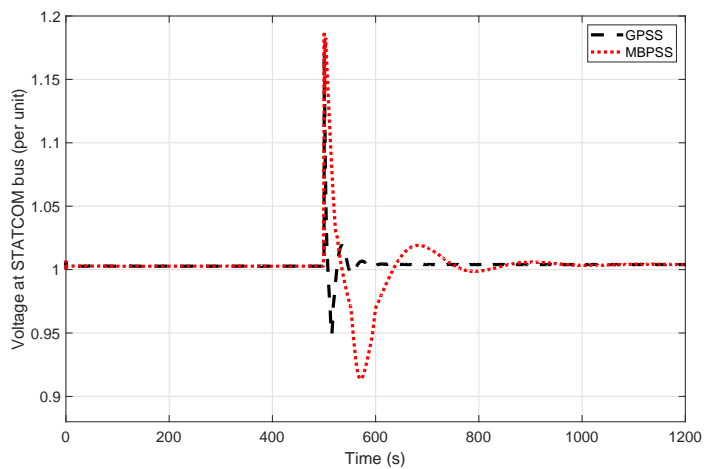

(e) STATCOM voltage.

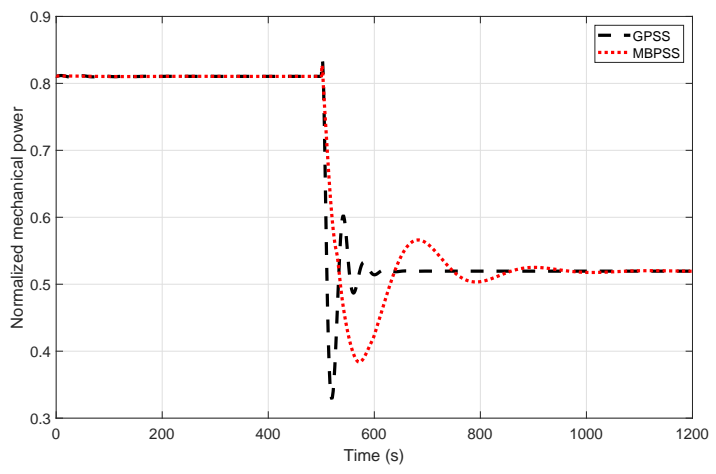

(g) Mechanical power of M2.

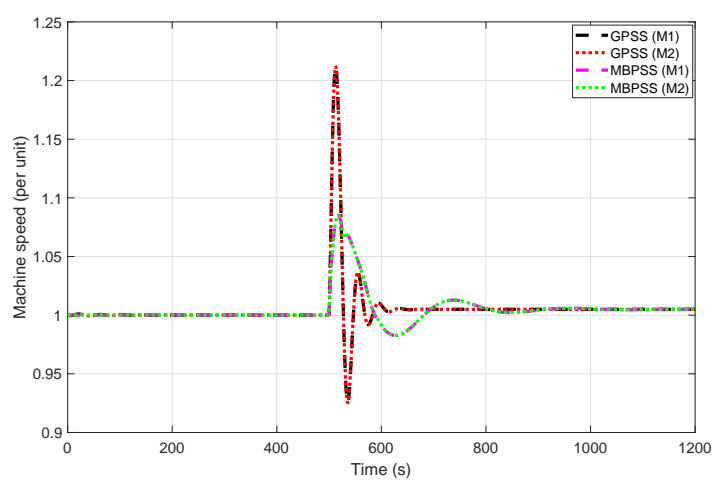

(b) Machine speed.

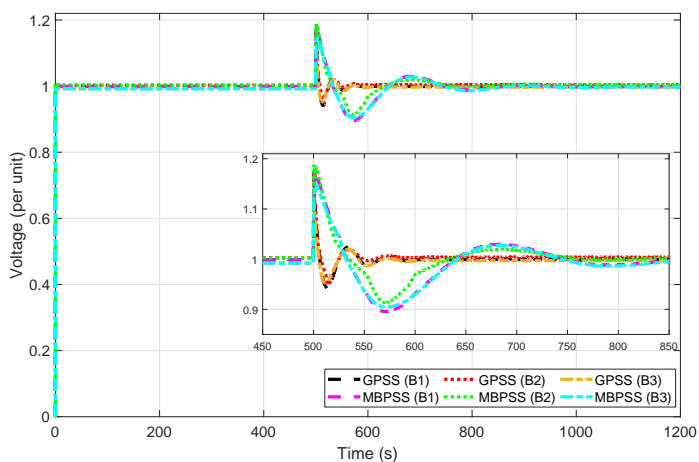

(d) Voltage positive sequence.

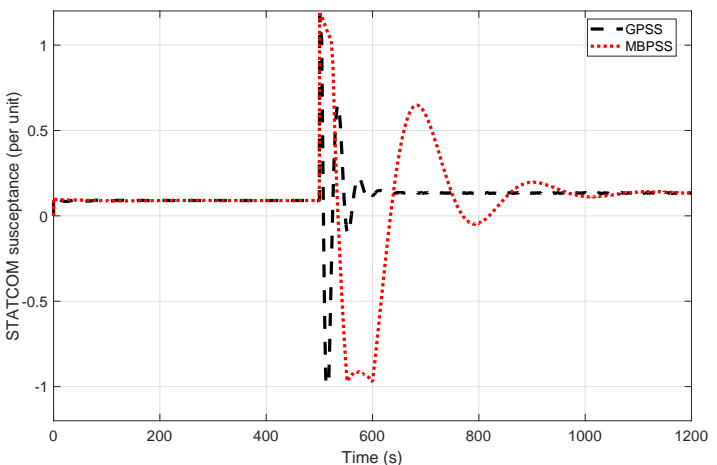

(f) STATCOM susceptance.

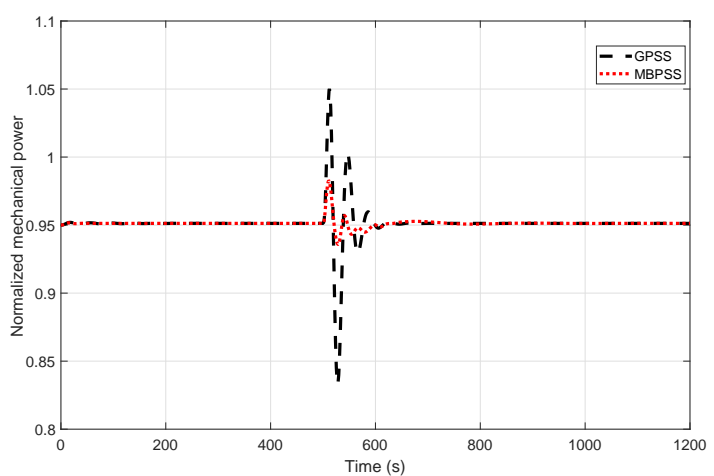

(h) Mechanical power of M1.

Figure 16. Case III.2: Variation in network signals during permanent load loss with generic and multiband PSS with STATCOM. 


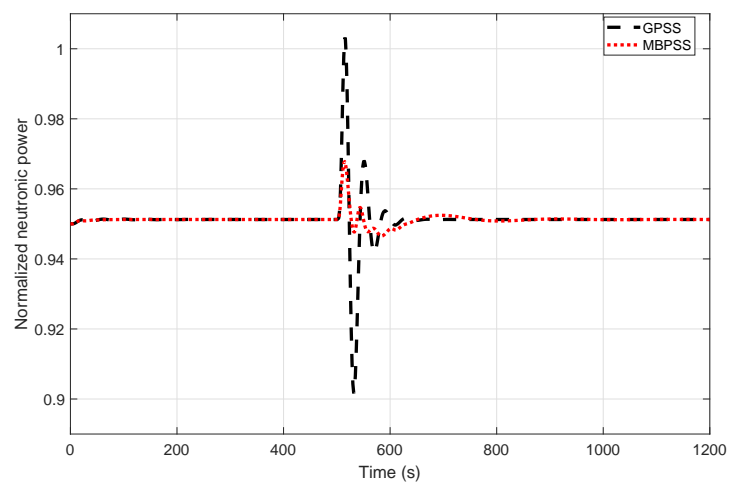

(a) Core neutronic power.

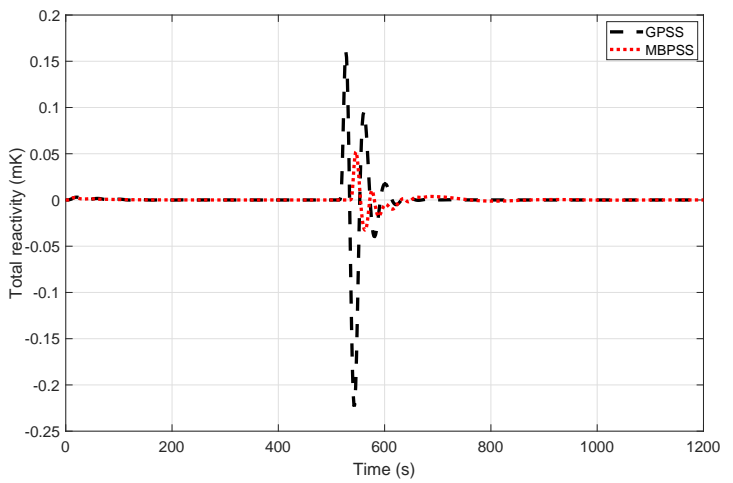

(c) Total reactivity.

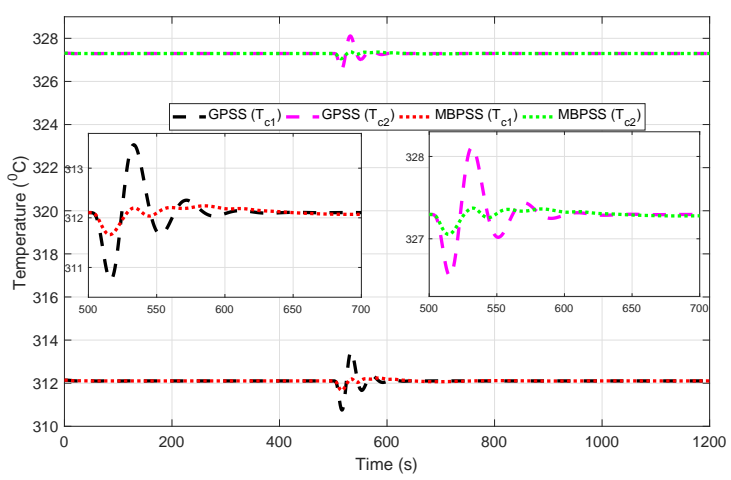

(e) Coolant temperature.

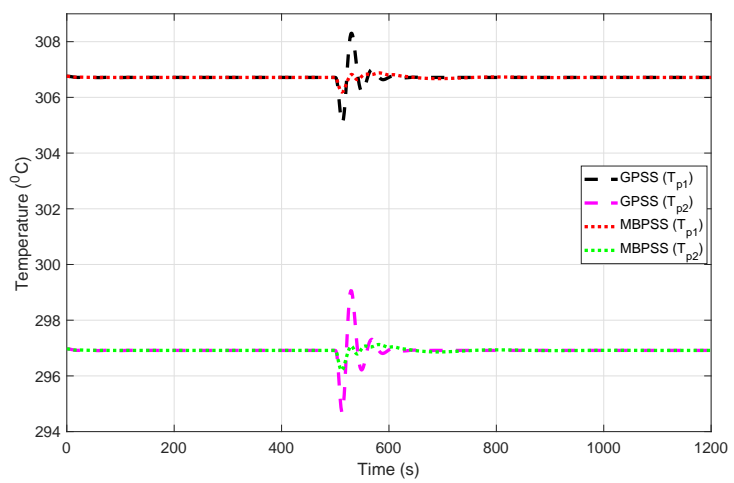

(g) Primary coolant lump temperature.

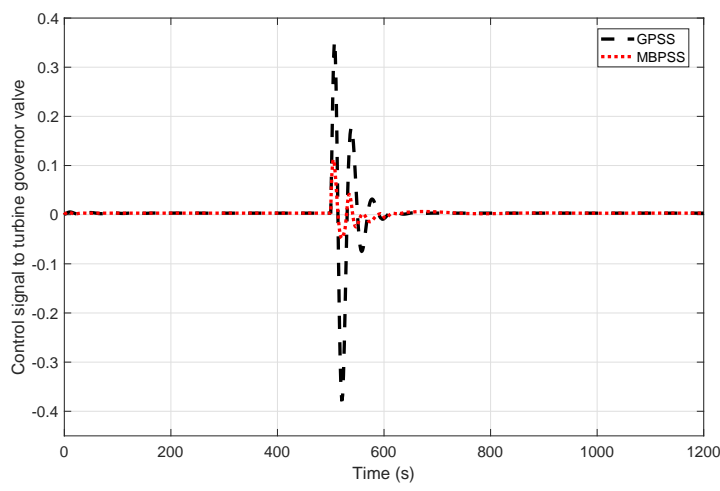

(b) Control signal to turbine governor valve.

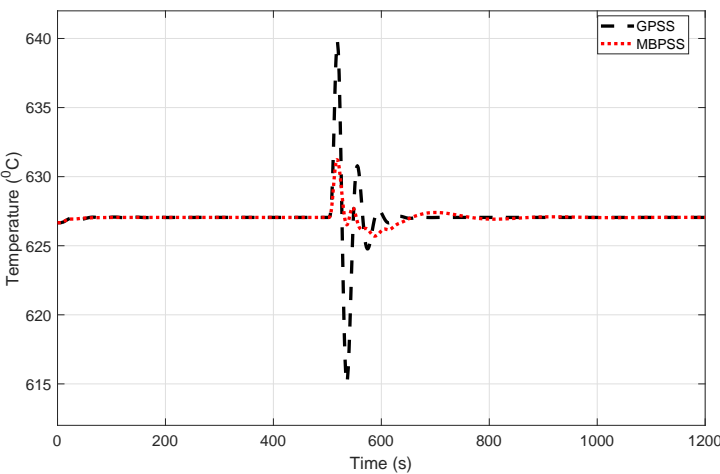

(d) Fuel temperature.

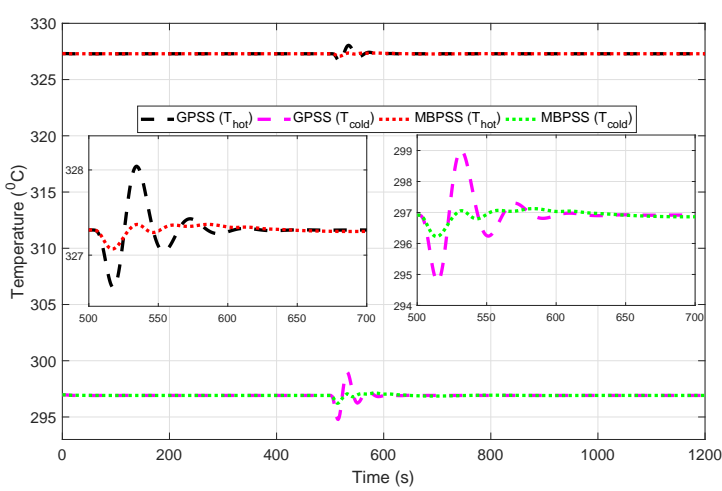

(f) Hot and cold legs temperature.

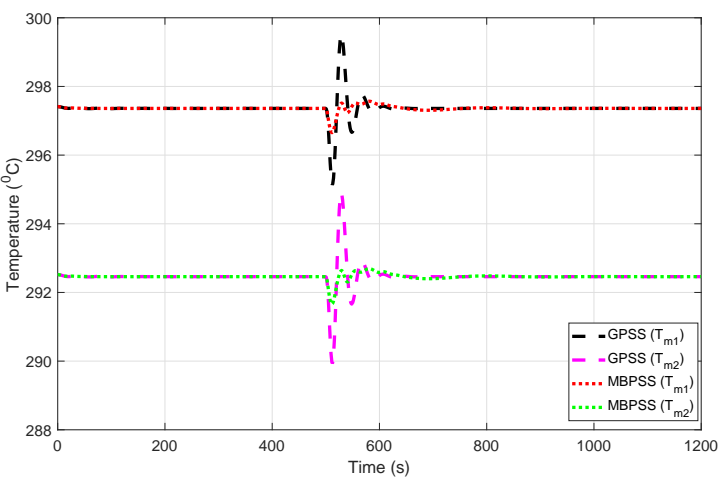

(h) Metal tube lump temperature.

Figure 17. Case III.2: Variation in nuclear power plant variables during permanent load loss with generic and multiband PSS with STATCOM. 


\section{Conclusions}

The transient analysis of a simulated pressurised water-type nuclear power plant connected to a faulted electric grid was presented in this work. The plant model consists of various integrated subsystems, such as the core, thermal hydraulics, piping and plenum, pressuriser, steam generator, turbine, governor, dynamics shaft, actuator, sensor, and turbine-speed controller. The interactions between the nuclear power plant, the electric grid, and protection systems were studied under various scenarios including multiple single-phase faults, multiple three-phase faults, and the permanent load-loss events affecting the electricity grid. The dynamic performance of the nonlinear plant and that of the grid were analysed in the presence of transient stability enhancement components such as power system stabilisers, static var compensators, and static synchronous compensators. Furthermore, the load-following operation of the power plant was studied. The effectiveness of different compensation mechanisms was demonstrated on the interconnected nuclear plant/grid model using various simulations in the MATLAB/Simulink/Simscape environment. In this regard, the presented work moves forward research on the safety, reliability, and operability aspects of nuclear power and thus forms a platform for future research on the analysis of transient effects of power grid faults and disturbances in a nuclear power plant and on the devices that can be employed to mitigate such effects.

Author Contributions: conceptualisation, V.V. and V.M.B.; methodology, V.V. and E.T.; software, V.V. and E.T.; validation, V.V. and E.T.; formal analysis, V.M.B.; investigation, V.V. and E.T.; resources, V.V., E.T., and V.M.B.; data curation, V.V., and E.T.; writing-original draft preparation, V.V. and E.T.; writing-review and editing, V.V. and V.M.B.; visualisation, V.V. and V.M.B.; supervision, V.M.B.; project administration, V.M.B.; funding acquisition, V.M.B. All authors have read and agreed to the published version of the manuscript.

Funding: This research was funded by the Engineering and Physical Sciences Research Council grant number EP/R022062/1.

Institutional Review Board Statement: Exclude this statement as the study did not involve humans or animals.

Informed Consent Statement: Exclude this statement as the study did not involve humans.

Data Availability Statement: Exclude this statement as the study did not report any data.

Conflicts of Interest: The authors declare no conflict of interest.

\section{Appendix A}

Table A1. Protection system and their standards.

\begin{tabular}{ll}
\hline Protection System & Standard \\
\hline $\begin{array}{l}\text { AC distribution system, Electrical circuit } \\
\text { protection, Diesel generator protection }\end{array}$ & IEEE Std 242-1986 \\
Motor protection system & IEEE Std 242-1986, IEEE Std C37.96-1988, \\
& IEEE Std 666-1991 \\
Power transformer protection & IEEE Std C37.91-1985, IEEE Std 666-1991 \\
Feeder circuit to power distribution & IEEE Std 141-1993, IEEE Std 242-1986 \\
panel protection & \\
Isolation and separation of non-class-1E & IEEE Std 384-1992 \\
circuits from class-1E circuits & \\
Surge protection of equipments and systems & IEEE Std 141-1993, IEEE Std 242-1986 \\
Surge protection of induction motors & IEEE Std C37.96-1988 \\
Protection of wire line facilities & IEEE Std 487-1992 \\
Circuits with solid-state equipments & IEEE Std 518-1982 \\
Surge arresters & IEEE Std C62.2-1987 \\
Surge voltage determination & IEEE Std C62.41-1991 \\
Surge withstand capability & IEEE Std C62.45-1992 \\
Protection for batteries & IEEE Std 946-1992 \\
Protection of battery chargers, inverters & IEEE Std 446-1987 \\
Ground protection practices & IEEE Std 142-1991, IEEE Std C62.92.3-1993 \\
Alarms and indication & IEEE Std 944-1986 \\
Electrical penetration & IEEE Std 317-1983 \\
\hline
\end{tabular}


Table A2. Parameter values of the components of the model.

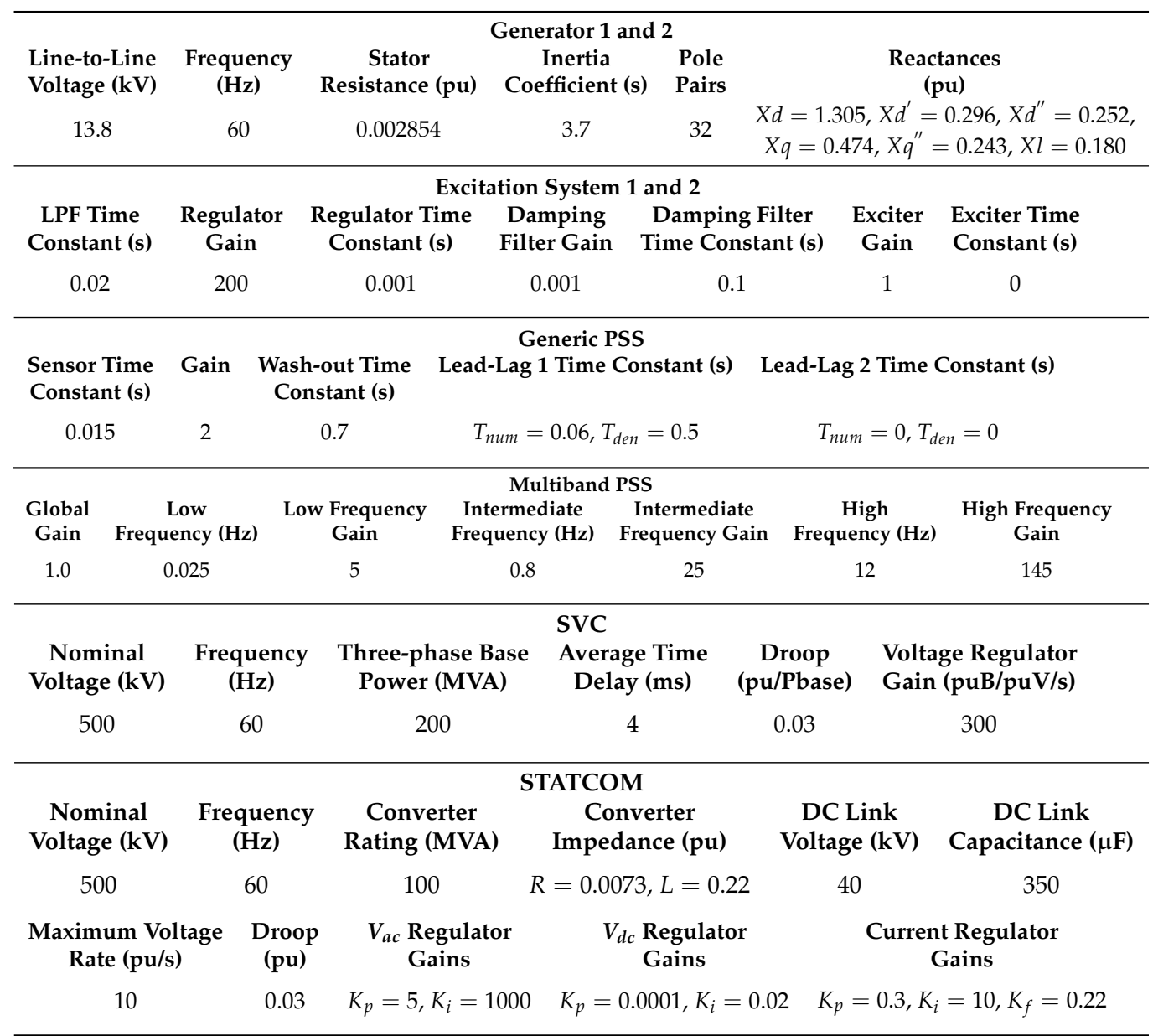

\section{References}

1. Maldonado, G.I. The performance of North American nuclear power plants during the electric power blackout of 14 August 2003. In Proceedings of the IEEE Symposium Conference Record Nuclear Science 2004, Rome, Italy, 16-22 October 2004; Volume 7, pp. 4603-4606.

2. Xuehao, H.; Xuecheng, Z.; Xiuming, Z.; Fulin, G.; Wenhua, Z. Pressurized water reactor nuclear power plant (NPP) modelling and the midterm dynamic simulation after NPP has been introduced into power system. In Proceedings of the TENCON ' 93 , IEEE Region 10 International Conference on Computers, Communications and Automation, Beijing, China, 19-21 October 1993; Volume 5, pp. 367-370.

3. Inoue, T.; Ichikawa, T.; Kundur, P.; Hirsch, P. Nuclear plant models for medium- to long-term power system stability studies. IEEE Trans. Power Syst. 1995, 10, 141-148. [CrossRef]

4. Ichikawa, T. Power Plant Dynamics Simulations Considering Interaction with Power System. In Proceedings of the IFAC Symposium on Control of Power Plants and Power Systems (CPSPP'97), Beijing, China, 18-21 August 1997; Volume 30, pp. 595-600.

5. Gao, H.; Wang, C.; Pan, W. A Detailed Nuclear Power Plant Model for Power System Analysis Based on PSS/E. In Proceedings of the 2006 IEEE PES Power Systems Conference and Exposition, Atlanta, GA, USA, 29 October-1 November 2006; pp. 1582-1586.

6. Li, X.; Liu, D.; Shi, X.; Zhao, J.; Wu, P. Research and Analyse for Pressurized Water Reactor Plant into Power System Dynamics Simulation. In Proceedings of the 2009 Asia-Pacific Power and Energy Engineering Conference, Wuhan, China, 28-30 March 2009; pp. 1-5.

7. Li, X.; Liu, D.; Wang, B.; Wu, P.; Zhao, J.; Shi, X. Dynamic characteristics analyse of pressurized water reactor Nuclear Power plant based on PSASP. In Proceedings of the 2009 4th IEEE Conference on Industrial Electronics and Applications, Xi'an, China, 25-27 May 2009; pp. 3629-3634.

8. Shi, X.; Wu, P.; Liu, D.; Li, X.; Zhao, J.; Zhang, Y.; Zhao, Z. Modeling and Dynamic Analysis of Nuclear Power Plant Reactor Based on PSASP. In Proceedings of the 2009 Asia-Pacific Power and Energy Engineering Conference, Wuhan, China, 28-30 March 2009; pp. 1-5.

9. Zhao, J.; Wu, P.; Liu, D. User-Defined Modeling of Pressurized Water Reactor Nuclear Power Plant Based on PSASP and Analysis of its Characteristics. In Proceedings of the 2009 Asia-Pacific Power and Energy Engineering Conference, Wuhan, China, 28-30 March 2009; pp. 1-6. 
10. Othman, S.; Mahmoud, H.M.; Kotb, S.A. Interaction of a Nuclear Power Plant With the Egyptian Electrical Grid Based on PSS/E. In Proceedings of the 18th International Conference on Nuclear Engineering, Xi'an, China, 17-21 May 2010; Volume 1, pp. 27-32.

11. Wu, G.; Song, X.; Lin, J.; Zhong, W.; Liu, T.; Ye, X.; Ju, P. Coordinated protection and control between large capacity nuclear power plants and power grids. In Proceedings of the 2013 IEEE Power Energy Society General Meeting, Vancouver, BC, Canada, 21-25 July 2013; pp. 1-5.

12. Ju, P.; Wu, F.; Chen, Q.; Han, J.; Dai, R.; Wu, G.; Tang, Y. Model Simplification of Nuclear Power Plant for Power System Dynamic Simulation. In Proceedings of the 2018 International Conference on Control, Artificial Intelligence, Robotics Optimization (ICCAIRO), Prague, Czech Republic, 19-21 May 2018; pp. 260-266.

13. Wen, L.; Sheng, W.; Xu, Z. Comparative analysis of external characteristics of nuclear power units and thermal power units. In Proceedings of the 2019 IEEE Innovative Smart Grid Technologies-Asia (ISGT Asia), Chengdu, China, 21-24 May 2019; pp. 1051-1056.

14. Wang, L.; Zhao, J.; Liu, D.; Lin, Y.; Zhao, Y.; Lin, Z.; Zhao, T.; Lei, Y. Parameter Identification with the Random Perturbation Particle Swarm Optimization Method and Sensitivity Analysis of an Advanced Pressurized Water Reactor Nuclear Power Plant Model for Power Systems. Energies 2017, 10, 173. [CrossRef]

15. Wu, G.; Ju, P.; Song, X.; Xie, C.; Zhong, W. Interaction and Coordination among Nuclear Power Plants, Power Grids and Their Protection Systems. Energies 2016, 9, 306. [CrossRef]

16. Wang, L.; Sun, W.; Zhao, J.; Liu, D. A Speed-Governing System Model with Over-Frequency Protection for Nuclear Power Generating Units. Energies 2020, 13, 173. [CrossRef]

17. Poudel, B.; Joshi, K.; Gokaraju, R. A Dynamic Model of Small Modular Reactor Based Nuclear Plant for Power System Studies. IEEE Trans. Energy Convers. 2020, 35, 977-985. [CrossRef]

18. International Atomic Energy Agency. Introducing Nuclear Power Plants into Electrical Power Systems of Limited Capacity: Problems and Remedial Measures; International Atomic Energy Agency: Vienna, Austria, 1987.

19. Kirby, B.; Kueck, J.; Leake, H.; Muhlheim, M. Nuclear Generating Stations and Transmission Grid Reliability. In Proceedings of the 2007 39th North American Power Symposium, Las Cruces, New Mexico, 30 September-2 October 2007; pp. $279-287$.

20. Wei-Jie, Z. Modeling and fault stability study for Million Kilowatts Nuclear Power Generator excitation system. In Proceedings of the 2014 International Conference on Power System Technology, Chengdu, China, 20-22 October 2014; pp. $244-250$.

21. Shafei, M.A.R.; Ibrahim, D.K.; El-Zahab, E.E.A. Transient stability enhancement of Egyptian national grid including nuclear power plant in Dabaa area. In Proceedings of the 2012 IEEE International Conference on Power and Energy (PECon), Kota Kinabalu, Malaysia, 2-5 December 2012; pp. 487-492.

22. Abou-El-Soud, A.; Elbanna, S.H.A.; SABRY, W. A Strong Action Power System Stabilizer Application in a Multi-machine Power System Containing a Nuclear Power Plant. In Proceedings of the 2019 16th Conference on Electrical Machines, Drives and Power Systems (ELMA), Varna, Bulgaria, 6-8 June 2019; pp. 1-6.

23. Kerlin, T.W. Dynamic Analysis and Control of Pressurized Water Reactors; Academic Press: Cambrige, MA, USA, 1978; Volume 14, pp. 103-212.

24. Ali, M.R.A. Lumped Parameter, State Variable Dynamic Models for U-Tube Recirculation Type Nuclear Steam Generators. Ph.D. Dissertation, University of Tennessee, Knoxville, TN, USA, 1976.

25. Naghedolfeizi, M. Dynamic Modeling of a Pressurized Water Reactor Plant for Diagnostics and Control. Master's Thesis, University of Tennessee, Knoxville, TN, USA, 1990.

26. Vajpayee, V.; Becerra, V.; Bausch, N.; Deng, J.; Shimjith, S.R.; Arul, A.J. Dynamic Modelling, Simulation, and Control Design of a Pressurized Water-type Nuclear Power Plant. Nucl. Eng. Des. 2020, 370, 110901. [CrossRef]

27. Milano, F. Power System Modelling and Scripting. In Power Systems; Springer: Berlin/Heidelberg, Germany, 2010.

28. Vajpayee, V.; Becerra, V.; Bausch, N.; Deng, J.; Shimjith, S.; Arul, A.J. Robust-optimal integrated control design technique for a pressurized water-type nuclear power plant. Prog. Nucl. Energy 2021, 131, 103575. [CrossRef]

29. Vajpayee, V.; Becerra, V.; Bausch, N.; Deng, J.; Shimjith, S.; Arul, A.J. LQGI/LTR based robust control technique for a pressurized water nuclear power plant. Ann. Nucl. Energy 2021, 154, 108105. [CrossRef]

30. Subudhi, C.S.; Bhatt, T.U.; Tiwari, A.P. A Mathematical Model for Total Power Control Loop of Large PHWRs. IEEE Trans. Nucl. Sci. 2016, 63, 1901-1911. [CrossRef]

31. Kundur, P.; Paserba, J.; Ajjarapu, V.; Andersson, G.; Bose, A.; Canizares, C.; Hatziargyriou, N.; Hill, D.; Stankovic, A.; Taylor, C.; et al. Definition and classification of power system stability IEEE/CIGRE joint task force on stability terms and definitions. IEEE Trans. Power Syst. 2004, 19, 1387-1401. [CrossRef]

32. Kundur, P. Power System Stability and Control; EPRI Power System Engineering Series McGraw-Hill: New York, NY, USA; 1994 .

33. Grondin, R.; Kamwa, I.; Soulieres, L.; Potvin, J.; Champagne, R. An approach to PSS design for transient stability improvement through supplementary damping of the common low-frequency. IEEE Trans. Power Syst. 1993, 8, 954-963. [CrossRef]

34. Zhang, X.P.; Rehtanz, C.; Pal, B. FACTS-Devices and Applications; Flexible AC Transmission Systems: Modelling and Control; Springer: Berlin/Heidelberg, Germany, 2012; pp. 1-30.

35. Hingorani, N.G.; Gyugyi, L. Understanding FACTS: Concepts and Technology of Flexible AC Transmission Systems; Wiley-IEEE Press: Piscataway, NJ, USA, 2000.

36. International Atomic Energy Agency. Electric Grid Reliability and Interface with Nuclear Power Plants; Number NG-T-3.8 in Nuclear Energy Series; International Atomic Energy Agency: Vienna, Austria, 2012. 
37. Łowczowski, K. Nuclear Power Plants in the National Power System. Acta Energet. 2018, 2, 70-75.

38. Mazzoni, O.S. Electrical Systems for Nuclear Power Plants; IEEE Press Wiley: Piscataway, NJ, USA, 2019.

39. IEEE. IEEE Standard for Criteria for the Protection of Class 1E Power Systems and Equipment in Nuclear Power Generating Stations; IEEE Std 741-2017 (Revision of IEEE Std 741-2007); IEEE Press Wiley: Piscataway, NJ, USA, 2017; pp. 1-63. 